\title{
The Taming of Redox-Labile Phosphidotitanocene Cations
}

\author{
Adrien T. Normand, ${ }^{[a] *}$ Quentin Bonnin, ${ }^{[a]}$ Stéphane Brandès, ${ }^{[a]}$ Philippe Richard, ${ }^{[a]}$ Paul Fleurat- \\ Lessard, ${ }^{[a]}$ Charles H. Devillers, ${ }^{[a]}$ Cédric Balan, ${ }^{[a]}$ Pierre Le Gendre, ${ }^{[a] *}$ Gerald Kehr ${ }^{[b]}$ and Gerhard \\ Erker $^{[b]}$
}

\begin{abstract}
: $d^{0}$ phosphidotitanocene cations stabilized with a pendant tertiary phosphane arm are reported. These compounds were obtained by one-electron oxidation of $\mathrm{d}^{1}$ precursors with $\left[\mathrm{Cp}_{2} \mathrm{Fe}\right]\left[\mathrm{BPh}_{4}\right]$. The electronic structure of these compounds was studied experimentally (EPR, UV-vis and NMR spectroscopy, X-ray diffraction analysis) and through DFT calculations. The theoretical analysis of the bonding situation using the Electron Localization Function (ELF) shows the presence of $\pi$ interactions between the phosphido ligand and $\mathrm{Ti}$ in the $\mathrm{d}^{0}$ complexes, whereas $d \pi-p \pi$ repulsion prevents such interactions in the $d^{1}$ complexes. In addition, $\mathrm{CH} / \pi$ interactions were observed in several complexes, both in solution and in the solid state, between the phosphido ligand and the phosphane arm. The $d^{0}$ complexes were found to be light sensitive, and decompose via Ti-P bond homolysis to give Ti(III) species. A naked $d^{0}$ phosphidotitanocene cation has been trapped by reaction with diphenylacetylene, yielding a Ti / P frustrated Lewis pair (FLP) which was found to be less reactive than a previously reported $\mathrm{Zr}$ analogue.
\end{abstract}

\section{Introduction}

Group 4 metal complexes bearing anionic phosphorus ligands have been investigated since the mid-1960s. ${ }^{[1]}$ Numerous studies focused on the reactivity and catalytic applications of $\mathrm{Zr}$ phosphinidene (A) and $\mathrm{Zr}$ phosphido (B) complexes (Scheme 1, $\mathrm{R}_{2} \mathrm{P}$ : phosphido; $\mathrm{RP}^{2-}$ : phosphinidene). ${ }^{[2],[3]}$ By contrast, the corresponding Ti complexes have been somewhat less explored; initially, most reports dealt with the synthesis and characterization of Ti phosphido complexes (B') - including P-bridged bimetallic compounds - with little emphasis on reactivity. ${ }^{[4]}$ Later reports by Harrod, Stephan and Le Gendre highlighted the importance of $\mathrm{Ti}$ phosphido species in catalytic dehydrocoupling and hydrophosphination reactions. ${ }^{[5]}$ Finally, $\mathrm{Ti}$ phosphinidene complexes $\left(\mathbf{A}^{\prime}\right)$ have been studied by Mindiola. ${ }^{[6]}$

[a] Dr. A. T. Normand, Dr Q. Bonnin, Dr S. Brandes, Dr P. Richard, Dr C. H. Devillers, C. Balan, Prof P. Le Gendre

ICMUB, Université de Bourgogne, UFR sciences et techniques, 9 rue Alain Savary - BP 47870, 21078 Dijon Cedex (France).

E-mail: adrien.normand@u-bourgogne.fr; pierre.le-gendre@ubourgogne.fr

[b] Dr G. Kehr, Prof.G. Erker

Organisch-Chemisches Institut, Universität Münster

Corrensstrasse 40, 48149 Münster (Germany)

Supporting information for this article is given via a link at the end of the document. CCDC 1871408-1871418 contain the supplementary crystallographic data for this paper. These data can be obtained free of charge from the Cambridge Crystallographic Data Centre via www.ccdc.cam.ac.uk/datarequest/cif.
We have recently reported on the chemistry of $d^{0}$ phosphidozirconocene cations $(\mathbf{C}){ }^{[7]}$ Compared to neutral complexes, these species display enhanced reactivity due to the combination of a coordinatively unsaturated $\mathrm{Cp}_{2} \mathrm{Zr}^{2+}$ fragment with a nucleophilic $\mathrm{PR}_{2}{ }^{-}$ligand. This reactivity can be exploited in i) the cooperative activation of $\mathrm{CO}_{2}$ and organic substrates; ii) the catalytic hydrogenation of olefins; iii) the synthesis of $\mathrm{Zr}^{+} / \mathrm{P}$ frustrated Lewis pairs (FLPs) by cycloaddition with alkynes. Unfortunately, we have thus far been unable to isolate these species and conduct more detailed investigations into the nature of the $\mathrm{Zr}-\mathrm{P}$ bond.

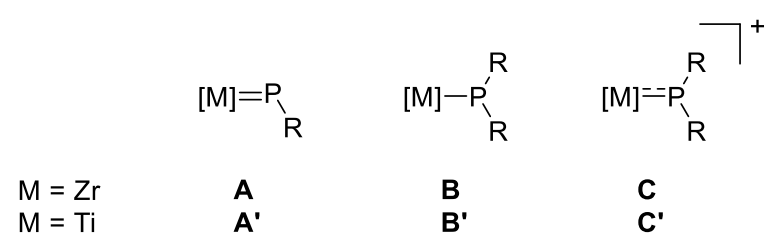

Scheme 1. Group 4 metal complexes with anionic phosphorus ligands.

In parallel to these studies, we have also been exploring the possibility to generate phosphidotitanocene cations (C'). Compared to the $\mathrm{Zr}$ analogues, these compounds require a different synthetic approach. Indeed, the salt metathesis route employed with $\mathrm{Zr}$ is unfeasible with $\mathrm{Ti}$, since $\mathrm{Ti}(\mathrm{IV})$ compounds are prone to one-electron reduction with concomitant production of a phosphinyl radical. ${ }^{[9]}$

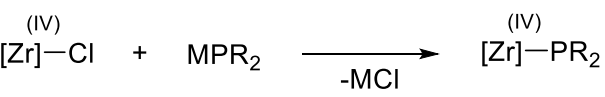

$$
\begin{aligned}
& \stackrel{(\mathrm{IV})}{[\mathrm{Ti}]-\mathrm{Cl}}+\mathrm{MPR}_{2} \underset{-\mathrm{MCl}}{[} \stackrel{\text { (III) }}{[\mathrm{Ti}]}+\cdot \mathrm{PR}_{2}
\end{aligned}
$$

Scheme 2. Reaction of group 4 metals with alkali metal phosphides $(M=L i, N a$, $\mathrm{K}) \cdot{ }^{[10]}$

As a consequence, examples of isolable Ti(IV) phosphido complexes are rather rare, ${ }^{[3 a-b],[11]}$ and to the best of our knowledge, experimentally characterized examples of $\mathrm{d}^{0}$ phosphidotitanocene complexes are unknown. However, we surmised that stable $d^{0}$ phosphidotitanocene cations might be obtained by oxidation of readily available neutral Ti(III) precursors containing a pendant phosphine arm (Scheme 3). ${ }^{[12]}$

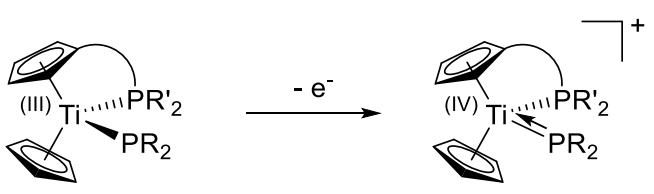

Scheme 3. Synthesis of $d^{0}$ phosphidotitanocene cations by one-electron oxidation of neutral $\mathrm{Ti}(\mathrm{III})$ precursors. 
In this paper, we report the successful application of this strategy and we address the question of the nature of the Ti-P bond in C' both experimentally and theoretically (DFT). Finally, we compare the reactivity of a FLP derived from an unsubstituted phosphidotitanocene cation with that of its previously reported $\mathrm{Zr}$ counterpart.

\section{Results and Discussion}

The synthesis of the target phosphidotitanocene cations can be effected in two steps from previously described $\left[\mathrm{Cp}^{\mathrm{P} C p T i C l} \mathrm{C}_{2}\right]$ complexes 1. ${ }^{[13]} \mathrm{Ti}(\mathrm{III})$ precursors were first prepared on 1-2 $\mathrm{mmol}$ scale by reacting 2 eq of lithium phosphide $\left(\mathrm{PPh}_{2} \mathrm{Li}\right.$ or $\left.\mathrm{PCy} \mathrm{L}_{2} \mathrm{Li}\right)$ with 1 (Scheme 4). ${ }^{[14]}$

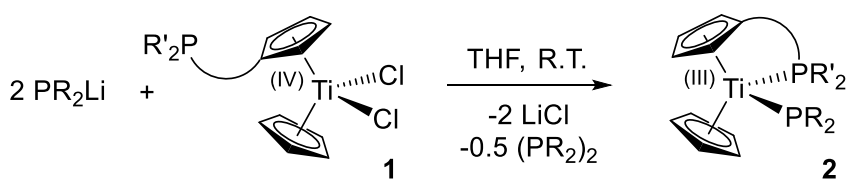

$$
\begin{array}{lll}
\mathrm{PRCy}_{2}= & \begin{array}{l}
\mathrm{R}=\mathrm{Ph} \\
\mathrm{R}=\mathrm{Ph}
\end{array} \\
\mathrm{PCy}_{2} & \mathbf{2 b}(774 \mathrm{mg}, 62 \%)
\end{array}
$$

Scheme 4. Synthesis of neutral Ti(III) precursors 2a-d.

Compounds $\mathbf{2 a - d}$ were obtained as green $(\mathbf{2 a}, \mathbf{2} \mathbf{b}, \mathbf{2} \mathbf{d})$ or brown (2c) solids in moderate yield. They were characterized by EPR spectroscopy, UV-vis spectroscopy, X-ray diffraction and elemental analysis.

Unlike the $\mathrm{TiCl}_{2}$ precursors 1a-d, compounds 2a-d all show an interaction between $\mathrm{Ti}$ and the pendant phosphine arm in the solid state (Figure 2). Table 1 provides a summary of relevant metric parameters; data for the analogous compound $\left[\mathrm{Cp}_{2} \mathrm{Ti}\left(\mathrm{PPh}_{2}\right)\left(\mathrm{PMe}_{3}\right](\mathrm{D})\right.$ previously reported by Stephan are also included for comparison. ${ }^{[4]}$
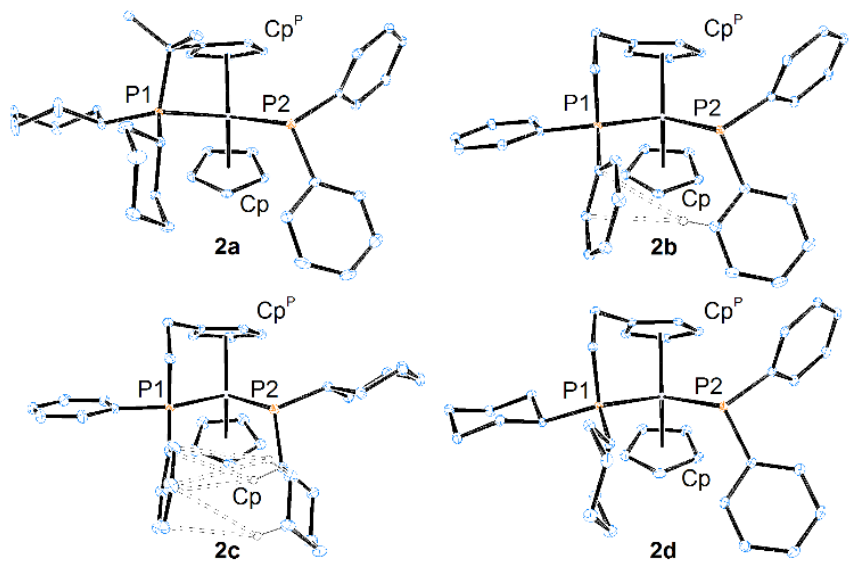

Figure 1. ORTEP drawings of the X-ray structures of 2a-d (ellipsoids drawn at the $30 \%$ probability level, hydrogen atoms removed for clarity, except where $\mathrm{CH}-\pi$ interactions are highlighted).
Table 1. Relevant bond lengths $[\AA]$ and angles $\left[^{\circ}\right]$ for $2 a-\mathbf{d}^{[a]}$

\begin{tabular}{lccccc}
\hline \multicolumn{1}{c}{$\mathbf{2 a}$} & $\mathbf{2 b}$ & $\mathbf{2 c}$ & $\mathbf{2 d}$ & $\mathbf{D}^{[\mathrm{b}]}$ \\
\hline $\mathrm{Ti}-\mathrm{Cp}^{\mathrm{P}}$ & $2.0556(12)$ & $2.0713(8)$ & $2.0802(9)$ & $2.0804(11)$ & $2.088(5)^{[\mathrm{c}]}$ \\
$\mathrm{Ti}-\mathrm{Cp}$ & $2.0528(14)$ & $2.0527(9)$ & $2.0612(9)$ & $2.0617(12)$ & $2.074(4)$ \\
$\mathrm{Ti}^{-\mathrm{P} 1^{[\mathrm{d}]}}$ & $2.6652(8)$ & $2.5990(6)$ & $2.6040(5)$ & $2.6499(8)$ & $2.636(3)$ \\
$\mathrm{Ti}^{\mathrm{P} 2} 2^{[\mathrm{dc}]}$ & $2.6636(8)$ & $2.6641(5)$ & $2.6247(6)$ & $2.6600(8)$ & $2.658(3)$ \\
$\mathrm{Cp}^{\mathrm{T} i-}$ & $137.40(5)$ & $135.99(3)$ & $135.24(4)$ & $134.44(4)$ & $133.18(19)$ \\
$\mathrm{Cp}^{\mathrm{P}}$ & & & & & \\
$\mathrm{P} 1-\mathrm{Ti}-$ & $93.40(2)$ & $85.33(2)$ & $79.76(2)$ & $86.02(2)$ & $86.02(9)$ \\
$\mathrm{P} 2$ & & & & & \\
$\Sigma \alpha(\mathrm{P} 2)$ & $319.6(2)$ & $322.5(1)$ & $333.8(1)$ & $325.3(2)$ & $324.5(5)$ \\
\hline
\end{tabular}

[a] $\mathrm{Cp}$ and $\mathrm{Cp}^{\mathrm{P}}$ indicate the centroid of the $\mathrm{Cp}$ and $\mathrm{Cp} \mathrm{p}^{\mathrm{P}}$ rings, respectively; [b] literature values; [c] Ti-Cp distance; [d] P1: phosphane ligand, P2: phosphido ligand.

The most salient structural feature of complexes $\mathbf{2 a - d}$ and $\mathbf{D}$ is the pseudo tetrahedral geometry of the phosphido ligand. This is reflected in the sum of angles around $P 1$, with values ranging from $319.6(2)^{\circ}(\mathbf{2 a})$ to $333.8(1)^{\circ}(\mathbf{2} \mathbf{c})$. Electronic repulsion between the phosphorus lone pair and the singly-occupied 1a1 orbital of the $d^{1}$ metal centre is most likely responsible for this geometry, ${ }^{[2 \mathrm{~d}],[15]}$ which should entail a trigonal planar phosphido ligand for the oxidized complexes (vide infra). The absence of $\pi-$ interactions between the phosphorus lone pair and the $\mathrm{Cp}_{2} \mathrm{Ti}$ fragment is also evident from $i$ ) the orientation of the phosphido ligand, ${ }^{[16]}$ and ii) the relatively long Ti-P2 distances (from $2.6247(6), 2 \mathbf{c}$, to $2.6641(5), \mathbf{2 b}$ ) which are close to the sum of covalent radii of $\mathrm{Ti}$ and $\mathrm{P}(2.67 \pm 0.11 \AA) .{ }^{[17]}$ These experimental findings are corroborated by theoretical calculations conducted on 2b (vide infra).

It is interesting to compare the structures of $\mathbf{2 b}$ and $\mathbf{2 c}$, since the latter features the considerably more basic and bulkier $\mathrm{PCy}_{2}$ (compared to $\mathrm{PPh}_{2}{ }^{-}$) phosphido ligand. First of all, the Ti-P2 distance in $\mathbf{2 c}$ is $0.039 \AA$ shorter compared to $\mathbf{2 b}$; the phosphido ligand is also somewhat flatter in $\mathbf{2 c}$, with a larger sum of angles around $\mathrm{P} 2\left(+11.3^{\circ}\right)$. It is tempting to ascribe these observations to increased $\pi$-interactions between $\mathrm{Ti}$ and $\mathrm{PCy}_{2}$, but the orientation of $\mathrm{PCy}_{2}-$ is not adequate for this purpose. A closer inspection of the structure of 2c suggests another explanation, namely $\mathrm{CH} / \pi$ interactions. ${ }^{[18]}$ Indeed, according to Nishio's formalism, $\mathbf{2 c}$ contains two Cy hydrogens in region 2 above one of the $\mathrm{Ph}$ rings of the phosphane arm, and one in region 1 (see the Supporting Information): therefore, these hydrogens satisfy the criteria for $\mathrm{CH} / \pi$ interactions. ${ }^{[19]}$ As a consequence, the Cy ring is brought closer to the phosphane arm, with concomitant flattening of the phosphido ligand, and shortening of the Ti-P2 distance. The narrower P1-Ti-P2 angle in 2c $\left(79.76(2)^{\circ}\right)$ compared to $\mathbf{2 b}\left(85.33(2)^{\circ}\right)$ is also likely a consequence of these interactions. Noteworthy, $\mathbf{2 b}$ also features a hydrogen atom in region 1 above one of the phosphane arm's $\mathrm{Ph}$ ring, however this is achieved simply by orienting both $\mathrm{Ph}$ rings in a perpendicular fashion. 
The X-band EPR spectra of 2a-d were recorded in THF and toluene at $295 \mathrm{~K}$. Due to the extreme moisture sensitivity of these compounds, hydrolysis products were generally observed in increasing amounts over time. The EPR spectrum of $\mathbf{2 b}$ in toluene shown in Figure 2 illustrates this phenomenon (see the supporting information for a detailed discussion).

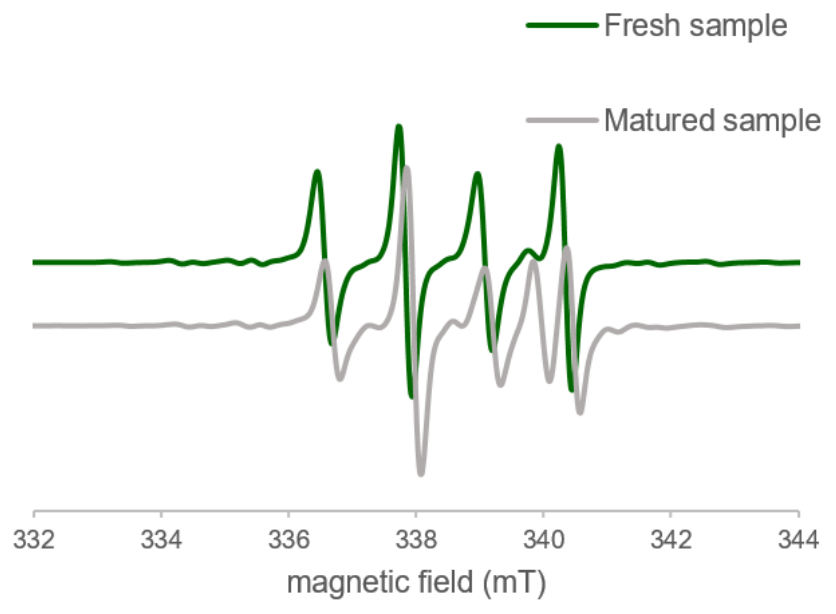

Figure 2. EPR spectrum of $\mathbf{2} \mathbf{b}$ in toluene showing the apparition of a hydrolysis product over time.

Relevant parameters (isotropic g-factor, hyperfine and superhyperfine coupling constants) are gathered in Table 2, along with data for D previously reported by Stephan. ${ }^{[4]]}$ Theoretical values were obtained by DFT calculations (see the Supporting Information for details).

Table 2. Relevant EPR parameters for $\mathbf{2 a - d} .^{[a]}$

\begin{tabular}{lccccc}
\hline & $\mathbf{2 a}$ & $\mathbf{2 b}$ & $\mathbf{2 c}$ & $\mathbf{2 d}$ & $\mathbf{D}^{[\mathrm{b}]}$ \\
\hline $\mathrm{g}$ & 1.9885 & 1.9911 & 1.9922 & 1.9895 & - \\
& 1.9885 & 1.9912 & 1.9922 & 1.9896 & 1.991 \\
Calc $^{[c]}$ & 1.9865 & 1.9884 & 1.9896 & 1.9856 & 1.988 \\
$\mathrm{~A}^{47 / 49 \mathrm{Ti}}$ & 9.0 & 8.7 & 8.3 & 9.1 & - \\
& 9.0 & 8.7 & 8.5 & 9.0 & 8.6 \\
Calc. $^{[c]}$ & 6.2 & 5.9 & 5.8 & 6.2 & 4.2 \\
$\mathrm{~A}^{31 \mathrm{P}}-1$ & 21.0 & 23.3 & 22.7 & 22.4 & - \\
& 21.3 & 23.3 & 22.3 & 22.3 & 24.4 \\
Calc. $^{[c]}$ & -20.9 & -19.9 & -19.1 & -17.7 & -29.8 \\
$\mathrm{~A}^{31 \mathrm{P}}-2$ & 6.3 & 11.0 & 16.3 & 4.8 & - \\
& 8 & 12.0 & 17.3 & 5.3 & 2.1 \\
Calc $^{[c]}$ & 9.9 & 15.4 & 15.7 & 10.5 & -6.3 \\
\hline
\end{tabular}

[a] spectra recorded in THF (first line) or toluene (second line) at $295 \mathrm{~K}$; a values in $10^{-4} \cdot \mathrm{cm}^{-1}[\mathrm{~b}]$ literature values, spectrum recorded in toluene at 298 K.[c] Computed in toluene.

Remarkably, the values of $g$ and $A$ for each compound are very similar in THF and toluene, which implies that phosphane coordination is retained in THF. This behaviour is also observed with the $d^{0}$ phosphidotitanocene cations (vide infra).
The absolute values of the coupling constant to the phosphido ligand ( $\left.A^{31 P}-2\right)$ range from 4.8 to $16.3 .10^{-4} \mathrm{~cm}^{-1}$ in THF. These are consistently smaller than the values of the coupling constant to the phosphane arm $\left(\mathrm{A}^{31 \mathrm{P}}-1\right)$, which span a much more restricted range of 21.0 to $22.7 .10^{-4} \mathrm{~cm}^{-1}$. These values are consistent with those found by Stephan for $\mathbf{D},{ }^{[4]}$ and they are a consequence of the higher $s$ character of the Ti-phosphane bond. Indeed, NBO calculations indicate $\sim 40 \%$ s character for the latter, vs $20 \%$ for the Ti-phosphido bond (see the Supporting Information).

The UV-vis absorption spectra of $\mathbf{2 a - d}$ in THF are characterized by local maxima $\left(\varepsilon=570-1410 \mathrm{~cm}^{-1} \cdot \mathrm{M}^{-1}\right)$ in the red to near IR region (Figure 3). ${ }^{[20]}$

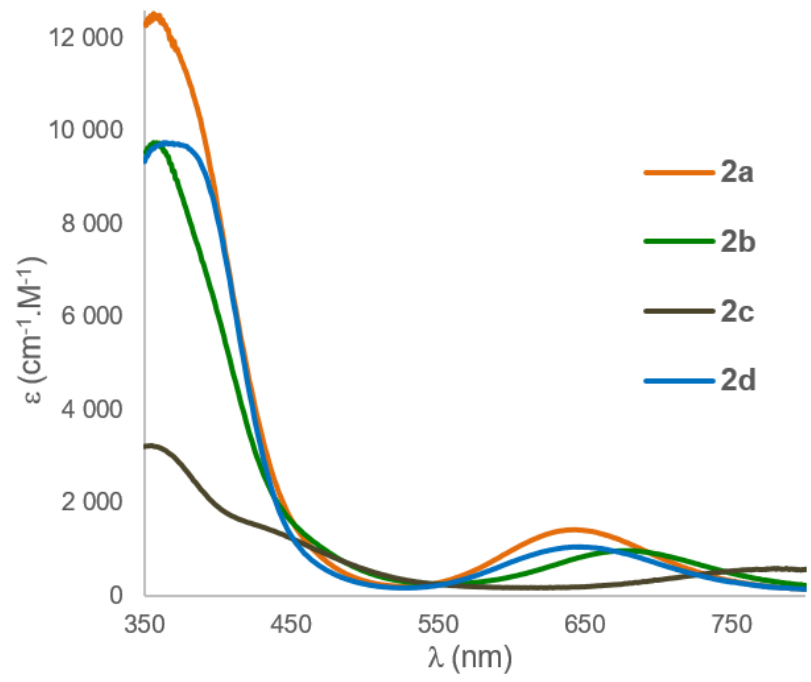

Figure 3. UV-vis spectra of $\mathbf{2 a - d}$ in THF.

As TD-DFT is not reliable for open-shell systems, ${ }^{[21]}$ we were unable to confidently analyse these transitions theoretically, and can therefore only speculate as to their exact nature.

We next turned our attention to the synthesis of the target phosphidotitanocene cations $\mathbf{3}$, following the oxidation route described above (Scheme 3). Thus, Ti(III) complexes 2a-d were oxidized with $\left[\mathrm{Cp}_{2} \mathrm{Fe}\right]\left[\mathrm{BPh}_{4}\right]$ in $\mathrm{C}_{6} \mathrm{H}_{5} \mathrm{Br}$, following a modification of a previously reported procedure. ${ }^{[13 b]}$
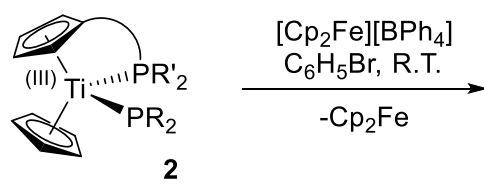

2<smiles>[R2]CCC</smiles>

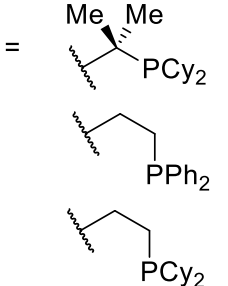

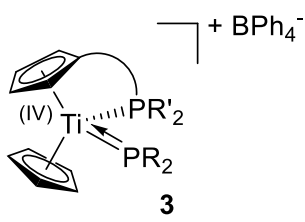

$\mathrm{R}=\mathrm{Ph} \quad 3 \mathbf{b}(708 \mathrm{mg}, 79 \%)$

$\mathrm{R}=\mathrm{Cy} \quad 3 \mathrm{c}(178 \mathrm{mg}, 59 \%)$

$\mathrm{R}=\mathrm{Ph} \quad$ 3d $(178 \mathrm{mg}, 50 \%)$
$\mathrm{R}=\mathrm{Ph} \quad 3 \mathrm{a} \quad \mathrm{X}$

Scheme 5. Synthesis of phosphidotitanocene cations $\mathbf{3 b - d}$

Complexes $\mathbf{3 b}$-d were isolated in good to moderate yield after workup (Scheme 5); however, complex 3a could not be isolated 
in pure form (the $\mathrm{Cp}$ region of the ${ }^{1} \mathrm{H}$ NMR spectrum showed the presence of impurities, and the mixture could not be purified).

We also attempted the synthesis of the unsubstituted phosphidotitanocene complex $\left[\mathrm{Cp}_{2} \mathrm{Ti}\left(\mathrm{PCy}_{2}\right)\right]\left[\mathrm{BPh}_{4}\right](3 e)$ following the oxidation route described in Scheme 4. Addition of two equivalents of $\mathrm{PCy} \mathrm{L}_{2} \mathrm{Li}$ to $\left[\mathrm{Cp}_{2} \mathrm{TiCl}_{2}\right]$ in $\mathrm{C}_{6} \mathrm{H}_{5} \mathrm{Br}$ followed by oxidation with $\left[\mathrm{Cp}_{2} \mathrm{Fe}\right]\left[\mathrm{BPh}_{4}\right]$ led to a mixture of dia- and paramagnetic species, possibly including the $\left[\mathrm{Cp}_{2} \mathrm{Ti}\left(\mathrm{PCy}_{2}\right)\left(\mathrm{PCy}_{2} \mathrm{H}\right)\right]^{+}$cation (see the Supporting Information). When we repeated this experiment in THF, the known compound $\left[\mathrm{Cp}_{2} \mathrm{Ti}(\mathrm{THF})_{2}\right]\left[\mathrm{BPh}_{4}\right]$ was isolated as blue crystals in $23 \%$ overall yield after recrystallization (Scheme 6). ${ }^{[22]}$ This complex was most probably formed by homolysis of the Ti-P bond according to Scheme 2.

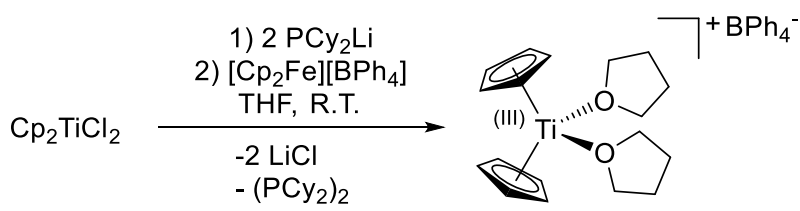

Scheme 6. Attempted syntheses of an unsubstituted $d^{0}$ phosphidotitanocene cation.

In light of the difficulties associated with the oxidation route, we attempted a different approach involving the protonolysis of the $\mathrm{Cp}_{2} \mathrm{TiMe}^{+}$cation with $\mathrm{PCy}_{2} \mathrm{H}$ (Scheme 7). Interestingly, this route did not afford $\mathbf{3 e}$, but instead compound $\mathbf{3 f}$, which contains a coordinated $\mathrm{PCy}_{2} \mathrm{H}$ ligand. Attempts at preparing $3 \mathrm{e}$ by using only 1 eq of $\mathrm{PCy}_{2} \mathrm{H}$ failed; rather, mixtures of $\mathbf{3 f}$ and $\mathrm{Cp}_{2} \mathrm{TiMe}^{+}$ were obtained. $\mathrm{APPh}_{2}$ analogue $(\mathbf{3 g})$ could also be synthesized, using $\mathrm{PPh}_{2} \mathrm{H}$ instead of $\mathrm{PCy}_{2} \mathrm{H}$.

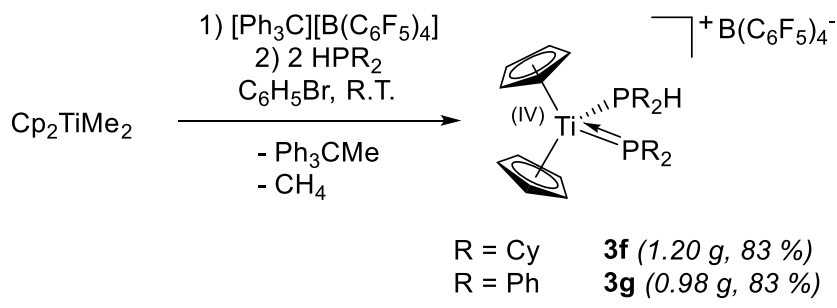

Scheme 7. Synthesis of $d^{0}$ phosphidotitanocene cations stabilized by secondary phosphanes.

Altogether, these results suggest that mixed phosphane / phosphidotitanocene cations are quite stable. Indeed, not only could complexes $3 b-f$ be isolated and studied spectroscopically (NMR, EPR, UV-vis), but X-ray structures were also obtained for 3b, $3 c$ and $3 e$ (Figure 4).

The impact of oxidation is evident upon examination of the solid-state structures of complexes $\mathbf{2 b} / \mathbf{3 b}$ and $\mathbf{2 c} / \mathbf{3 c}$ (Tables 1 and 3). The Ti-P2 distance is $0.30 \AA$ shorter in $\mathbf{3 b}$ vs $\mathbf{2} \mathbf{b}$, and 0.26 $\AA$ shorter in 3c vs 2c. Additionally, the phosphido ligand in complexes $\mathbf{3}$ is now much closer to a trigonal planar geometry than in complexes 2, thus bringing the phosphorus lone pair closer to $\mathrm{Ti}\left(\Sigma \alpha(\mathrm{P} 2)=358.9(3)\right.$ to $\left.360.0(4)^{\circ}\right)$. Moreover, the orientation of the phosphido ligand (torsion angle $\varphi$ ) also brings the lone pair into the same plane as the empty 1a1, b2 and 2a1 orbitals on Ti. ${ }^{[23]}$ The unconstrained $\mathrm{PPh}_{2} \mathrm{H}$ complex $3 \mathrm{e}$ is a case in point, with a Ti-P2 bond distance of 2.3611 (18) $\AA$ (much shorter than the $2.67 \pm 0.11 \AA$ sum of covalent radii), a perfectly trigonal planar phosphido ligand $\left(\Sigma \alpha(\mathrm{P} 2)=360.0(4)^{\circ}\right)$ and an almost perfect alignment of donor-acceptor orbitals $\left(\varphi=-2.3(3)^{\circ}\right)$. These changes are especially remarkable if one considers that other parameters (e.g. Ti-P1 distances), hardly change upon oxidation.
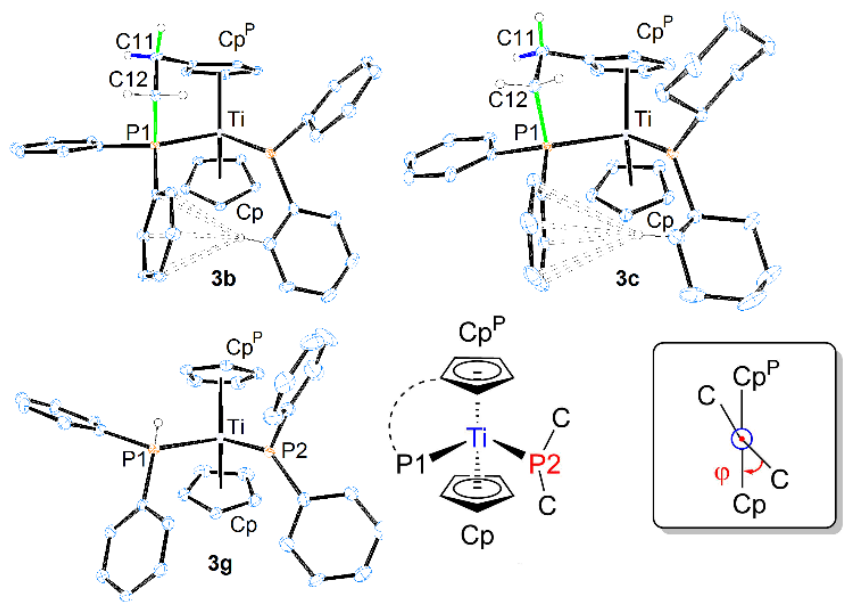

Figure 4. ORTEP drawings of the X-ray structures of $\mathbf{3 b} \mathbf{b} \mathbf{g}$ (ellipsoids drawn at the $30 \%$ probability level, $\mathrm{BPh}_{4}{ }^{-}$anion and most hydrogen atoms removed for clarity) and definition of the torsion angle $\varphi$.

Table 3. Relevant bond lengths $[\AA \AA \AA]$ and angles $\left[^{\circ}\right]$ for $3 \mathbf{b}, \mathbf{3 c}$ and $3 e^{[a]}$

\begin{tabular}{|c|c|c|c|}
\hline & $3 b$ & $3 c$ & $3 e$ \\
\hline Ti-Cp ${ }^{P}$ & $2.0471(18)$ & $2.0497(9)$ & $2.051(3)^{[c]}$ \\
\hline Ti-Cp & $2.040(3)$ & $2.0438(9)$ & $2.042(3)$ \\
\hline $\mathrm{Ti}-\mathrm{P} 1^{[\mathrm{d}]}$ & $2.5883(12)$ & $2.6062(5)$ & $2.5868(17)$ \\
\hline $\mathrm{Ti}-\mathrm{P} 2^{[\mathrm{d}]}$ & $2.3599(14)$ & $2.3646(6)$ & $2.3611(18)$ \\
\hline Cp-Ti-Cp $p^{P}$ & $135.20(9)$ & $133.77(4)$ & $134.89(12)$ \\
\hline P1-Ti-P2 & $90.72(4)$ & $89.26(2)$ & $88.83(6)$ \\
\hline$\Sigma \alpha(\mathrm{P} 2)$ & $358.9(3)$ & $359.98(12)$ & $360.0(4)$ \\
\hline$\varphi$ & $16.09(19)$ & $-15.85(8)$ & $-2.3(3)$ \\
\hline
\end{tabular}

[a] $\mathrm{Cp}$ and $\mathrm{Cp}^{\mathrm{P}}$ indicate the centroid of the $\mathrm{Cp}$ and $\mathrm{Cp}^{\mathrm{P}}$ rings, respectively; [b] literature values; [c] Ti-Cp distance; [d] P1: phosphane ligand, P2: phosphido ligand.

Therefore, there is considerable structural evidence to support the hypothesis of $\pi$ interactions between $\mathrm{Ti}$ and the phosphido ligand in complexes 3 . This is confirmed through the theoretical analysis of the Ti-P interactions in $\mathbf{2 b}$ and $\mathbf{3 b}$ (see Computational Details): in $\mathbf{2 b}$, only one lone pair of the phosphido ligand is involved in a Ti-P bond, while both are interacting with the titanium atom in $\mathbf{3 b}$ (Figure 5) indicating $\boldsymbol{\pi}$ interactions in these complexes. ${ }^{[24]}$ This is in line with previous theoretical results obtained on hypothetical $d^{0}$ phosphidotitanocene complexes. ${ }^{[12]}$

A deeper analysis of the $X$-ray structures of $\mathbf{3 b}$ and $\mathbf{3 c}$ reveals yet more interesting features. Firstly, as in the case of $\mathbf{2} \mathbf{b}$ and $\mathbf{2 c}$, $\mathrm{CH} / \pi$ interactions are observed between one of the $\mathrm{Ph}$ rings of 
the phosphane arm and $\mathrm{CH}$ bonds on the phosphido ligand (Figure 4). Both hydrogens are located in region 1 above the $\mathrm{Ph}$ rings (see the Supporting Information). Interestingly, in the case of $\mathbf{3 c}$, this does not seem to induce a narrower P1-Ti-P2 angle as in 2c. Rather, since the Cy ring is engaged in only one $\mathrm{CH} / \pi$ interaction with the $\mathrm{Ph}$ ring, both rings adopt a perpendicular orientation, as observed with the $\mathrm{Ph}$ rings of $\mathbf{2} \mathbf{b}$ and $\mathbf{3} \mathbf{b}$.

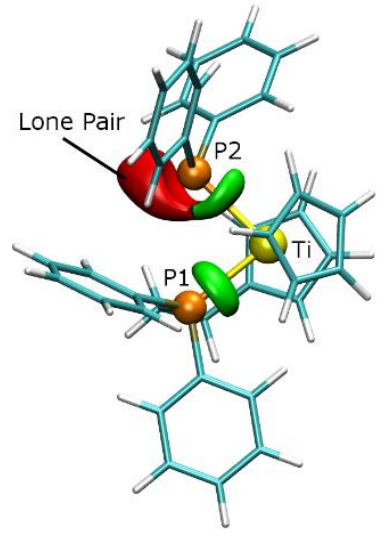

2b

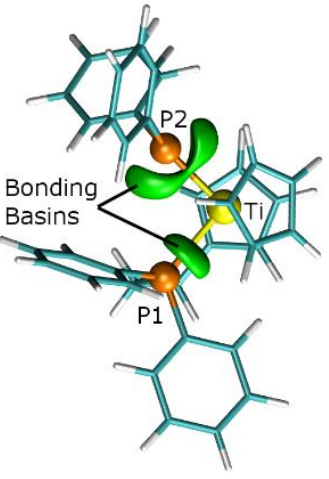

$3 b$
Figure $\mathbf{5}$. ELF basins in $\mathbf{2 b}$ and $\mathbf{3 b}$. Bonding basin are shown in green whilst lone pairs are in red. For clarity's sake, only the basins between $\mathrm{Ti}$ and $\mathrm{P}$ are shown, and the $\mathrm{BPh}_{4}^{-}$anion is omitted.

Secondly, the chelate ring formed by the phosphane arm causes one of the $\mathrm{CH}$ bonds of the $\mathrm{CH}_{2}$ group attached to the $\mathrm{Cp}$ ring to become almost anti-periplanar to the $\mathrm{P} 1-\mathrm{CH}_{2}$ bond (Figure $6)$.

$$
\begin{array}{ll}
\theta_{1} \sim 180^{\circ} \\
\theta_{2} \sim 60^{\circ}
\end{array}
$$

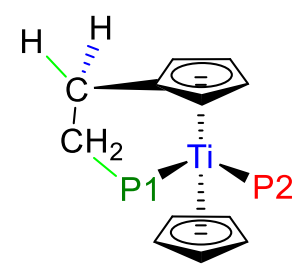

Figure 6. Definition of torsion angles $\theta_{1}$ and $\theta_{2}$.

Examination of the ${ }^{1} \mathrm{H}$ NMR spectrum of $\mathbf{3 b}$ and $\mathbf{3 c}$ indicates that this conformation is retained in solution. Indeed, Figure 7 shows the aliphatic region of the ${ }^{1} \mathrm{H}$ and ${ }^{1} \mathrm{H}\left\{{ }^{31} \mathrm{P}\right\}$ spectra of $\mathbf{3 b}$ : the hydrogens of the $\mathrm{Cp}-\mathrm{CH}_{2}$ group resonate at 2.87 and $2.04 \mathrm{ppm}$, with ${ }^{3} \mathrm{JPH}_{\mathrm{PH}}$ coupling constants of 44.9 and $5.5 \mathrm{~Hz}$ (Table 4). ${ }^{[25]}$ Since ${ }^{3} \mathrm{~J}$ coupling between $\mathrm{P}$ and $\mathrm{H}$ nuclei follows a Karplus relationship, with a maximum corresponding to anti-periplanar arrangement of $\mathrm{P}-\mathrm{C}$ and $\mathrm{C}-\mathrm{H}$ bonds, ${ }^{[26]}$ we conclude that the conformation of the ethylene arm of $\mathbf{3 b}$ is similar in solution and in the solid state. ${ }^{[27]}$ The same conclusions can also be drawn for $\mathbf{3 c}$.

The $\mathrm{CH} / \pi$ interactions observed in the X-ray structures of $\mathbf{3 b}$ and $3 \mathbf{c}$ should entail considerably shielded ${ }^{1} \mathrm{H}$ NMR signals for the hydrogens involved, due to aromatic ring current effects. Indeed, in the case of $\mathbf{3 b}$, the ortho hydrogens of one of the $\mathrm{Ph}$ ring of the phosphido ligand resonate as a triplet at $6.25 \mathrm{ppm}$ in $\mathrm{CD}_{2} \mathrm{Cl}_{2}(500$ $\mathrm{MHz}, 300 \mathrm{~K}$ ), whereas the same hydrogens resonate above 7.28 ppm in 3d (Figure 8). ${ }^{[28]}$ However, $\mathrm{CH}-\pi$ interactions are not strong enough to prevent the free rotation of the $\mathrm{Ph}$ ring of the phosphido ligand.

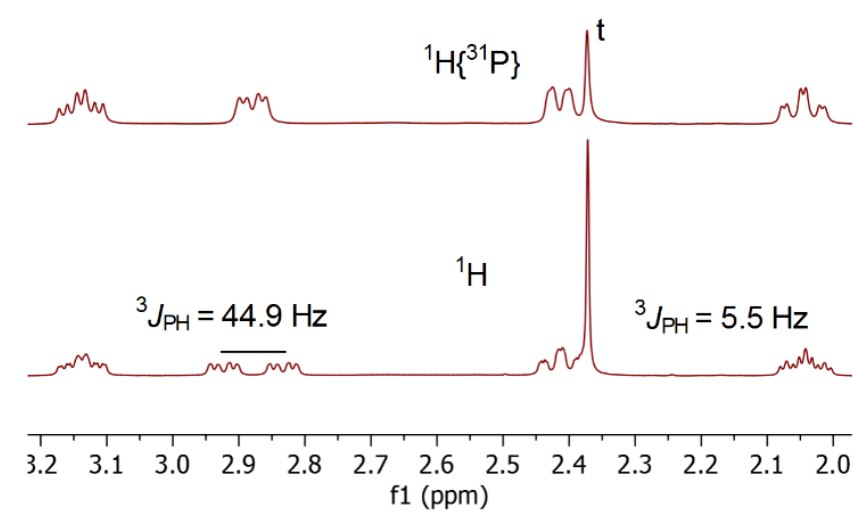

Figure 7. Aliphatic region of the ${ }^{1} \mathrm{H}$ and ${ }^{1} \mathrm{H}\left\{{ }^{31} \mathrm{P}\right\}$ spectra of $\mathbf{3 b}$ in $\mathrm{CD}_{2} \mathrm{Cl}_{2}(500$ $\mathrm{MHz}, 300 \mathrm{~K}$ ) showing ${ }^{3} \mathrm{~J}$ coupling between $\mathrm{P}$ and $\mathrm{H}$ nuclei (t: residual toluene signal).

Table 4. Values of $\theta(X R D)$ and ${ }^{3} J_{P H}(N M R)$ for $3 b$ and $3 c$. [a]

\begin{tabular}{lllll}
\hline & $\theta_{1}\left({ }^{\circ}\right)$ & $\theta_{2}\left({ }^{\circ}\right)$ & ${ }^{3} \mathrm{JPH}-1(\mathrm{~Hz})$ & ${ }^{3} \mathrm{JHH}_{\mathrm{P}} \mathrm{C}(\mathrm{Hz})$ \\
\hline 3b & $172.1(3)$ & $-69.5(4)$ & 44.9 & 5.5 \\
3c & $-174.66(12)$ & $67.08(16)$ & 43.5 & 6.1 \\
\hline
\end{tabular}

[a] ${ }^{1} \mathrm{H}$ spectra recorded at $500 \mathrm{MHz}$ in $\mathrm{CD}_{2} \mathrm{Cl}_{2}, 300 \mathrm{~K}$.

In the case of $3 \mathbf{c}$, a shielded signal $(0.00 \mathrm{ppm})$ is observed in $\mathrm{CD}_{2} \mathrm{Cl}_{2}(500 \mathrm{MHz}, 300 \mathrm{~K})$ for one of the $\mathrm{CH}_{2}$ hydrogens of the $\mathrm{Cy}$ ring. Interestingly, a shielded signal is also observed in $d_{8}$-THF (0.06 ppm) and $\mathrm{C}_{6} \mathrm{D}_{5} \mathrm{Br}(-0.17 \mathrm{ppm})$. The conformation of this complex appears to be frozen in these solvents at $300 \mathrm{~K}$, since only one hydrogen experiences a shielding effect (probably because of steric congestion due to the Cy ring).
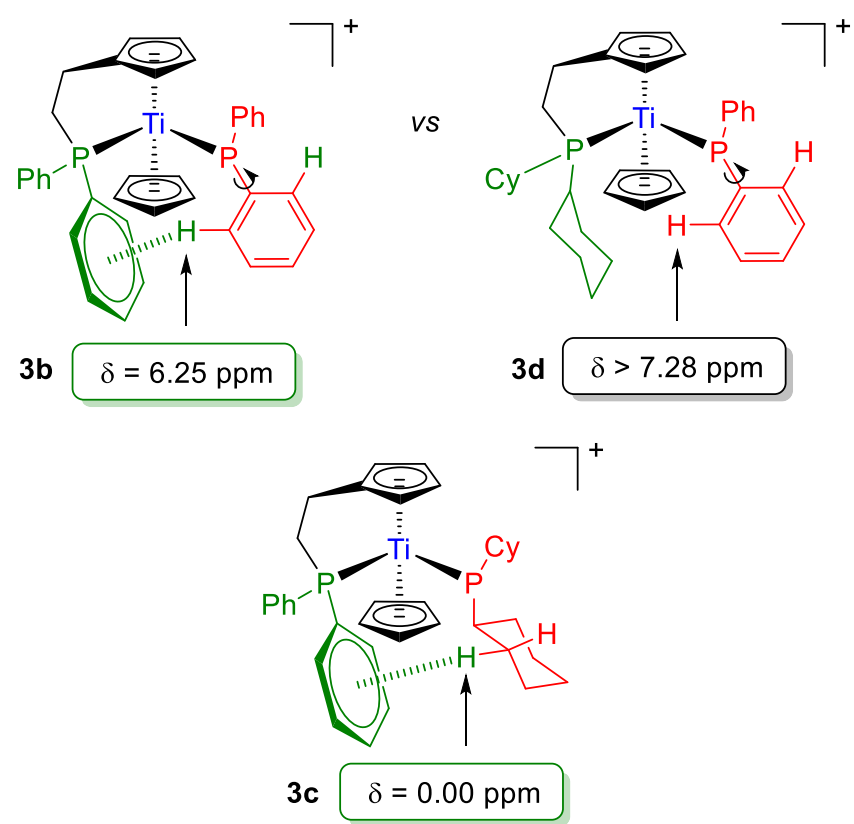

Figure 8. Conformational origin of shielded ${ }^{1} \mathrm{H}$ NMR signals in $\mathbf{3 b}$ and $3 \mathbf{c}$ $\left(\mathrm{CD}_{2} \mathrm{Cl}_{2}, 500 \mathrm{MHz}, 300 \mathrm{~K}\right)$. $\mathrm{BPh}_{4}^{-}$anions omitted for clarity. 
In summary, there is considerable evidence to suggest that the structures of $\mathbf{3 b}$ and $\mathbf{3 c}$ are the same in solution and in the solid state. This correspondence indicates that the $\mathrm{Cp}^{\mathrm{P} C p T i}$ fragment $\left(\mathrm{Cp}^{\mathrm{P}}=\mathrm{C}_{5} \mathrm{H}_{5}-\mathrm{CH}_{2} \mathrm{CH}_{2} \mathrm{PPh}_{2}\right)$ may be viewed as a preorganized host for $\mathrm{CH} / \pi$ interactions with incoming ligands or substrates. Noteworthy, the neutral $d^{1}$ analogues are also preorganized, since the X-ray structures of $\mathbf{2 b}$ and $\mathbf{2} \mathbf{c}$ show $\mathrm{CH} / \pi$ interactions as well.

The ${ }^{31} \mathrm{P}\left\{{ }^{1} \mathrm{H}\right\}$ NMR spectra of $\mathbf{3 b} \mathbf{b} \mathbf{g}$ are also interesting in a number of ways. First of all, the signals corresponding to the phosphido ligand are very deshielded, around $410 \mathrm{ppm}$ for $\mathrm{PPh}_{2}$ and $500 \mathrm{ppm}$ for $\mathrm{PCy}_{2}^{-}$(Table 5). For comparison, the $\left[\mathrm{Cp}_{2} \mathrm{ZrPCy}_{2}\right]^{+}$cation (C1) gave a more shielded signal at 396.6 ppm $\left(\mathrm{C}_{6} \mathrm{D}_{5} \mathrm{Br}, 202 \mathrm{MHz}, 299 \mathrm{~K}\right) .{ }^{[7 \mathrm{a}]}$ In a recent paper, Eisenstein noted that neutral $\mathrm{d}^{0}$ alkylidene complexes - which are valence isoelectronic to cationic $d^{0}$ phosphido complexes - display considerably deshielded ${ }^{13} \mathrm{C}$ NMR signals, similar to carbocations despite their nucleophilic carbene character. ${ }^{[29]}$ The major conclusion of that study was that the observed deshielding of the carbene signal (compared to ethylene) was the result of more efficient coupling between $\sigma_{M C}$ (ligand based) and $\pi^{*}{ }_{M C}$ (metal based) orbitals, which are separated by a narrower gap than the $\sigma_{c c}$ and $\pi^{*}{ }_{C c}$ orbitals of ethylene. Consequently, $d^{0}$ alkylidene complexes of $5 \mathrm{~d}$ metals give less deshielded carbene signals than isoelectronic $4 d$ metals complexes, due to the higher energy of $5 d$ vs $4 \mathrm{~d}$ empty orbitals. Although this would fall outside the scope of the present paper, it would be interesting - in light of the Eisenstein study - to investigate whether similar explanations apply to i) the highly deshielded ${ }^{31} \mathrm{P}$ NMR signal of phosphidometallocene cations $\mathbf{3 b}$-f and $\mathbf{C} \mathbf{1}$, and ii) the $\sim 100 \mathrm{ppm}$ difference between $\mathrm{Ti}(3 \mathrm{~d})$ and $\mathrm{Zr}(4 \mathrm{~d})$ complexes.

Table 5. Relevant ${ }^{31} \mathrm{P}\left\{{ }^{1} \mathrm{H}\right\}$ NMR parameters for $\mathbf{3 b}$-g. ${ }^{[\mathrm{a}]}$

\begin{tabular}{llllll}
\hline & 3b & 3c & 3d & 3g & 3f \\
\hline $\begin{array}{l}\delta-P 1^{[b]} \\
(\mathrm{ppm})\end{array}$ & 45.2 & 43.8 & 52.3 & 23.7 & 39.1 \\
& 44.9 & 43.2 & 52.2 & N.A. ${ }^{[\mathrm{c}]}$ & N.A. ${ }^{[\mathrm{c}]}$ \\
$\delta-\mathrm{P} 2$ & 414.1 & 506.4 & 401.2 & $420.2^{[\mathrm{c}]}$ & $500.4^{[\mathrm{c}]}$ \\
$(\mathrm{ppm})$ & 408.8 & 496.7 & 395.1 & N.A. ${ }^{[\mathrm{d}]}$ & N.A. ${ }^{[\mathrm{d}]}$ \\
& & & & & \\
${ }^{2} \mathrm{JPP}$ & 70.2 & 71.7 & 64.0 & 83.0 & 76.7 \\
$(\mathrm{~Hz})$ & 68.7 & 70.6 & 63.0 & N.A. ${ }^{[\mathrm{c}]}$ & N.A. ${ }^{[\mathrm{cc}]}$ \\
\hline
\end{tabular}

[a] spectra recorded in $\mathrm{CD}_{2} \mathrm{Cl}_{2}$ (first line) or $\mathrm{d}_{8}$-THF (second line) at 202 $\mathrm{MHz}, 300 \mathrm{~K}$; [b] P1: phosphane ligand, P2: phosphido ligand; [c] spectra recorded in $\mathrm{C}_{6} \mathrm{D}_{5} \mathrm{Br}$; [d] $\mathbf{3 e}$ and $\mathbf{3 f}$ decomposed in THF.

Another striking feature of complexes $3 \mathbf{b}-\mathbf{f}$, visible in their ${ }^{31} \mathrm{P}\left\{{ }^{1} \mathrm{H}\right\}$ spectra, is the stability conferred by the chelating phosphane arm in a coordinating solvent such as $d_{8}$-THF. Indeed, complexes $\mathbf{3 b}$-d remain unaltered in this solvent, as evidenced by the similar chemical shifts of $\mathrm{P} 1$ and $\mathrm{P} 2$ in $\mathrm{CD}_{2} \mathrm{Cl}_{2}$ vs $\mathrm{d}_{8}$-THF on the one hand, and the ${ }^{2} J_{\mathrm{PP}}$ coupling constants on the other hand (64.0 to $71.7 \mathrm{~Hz}$ in $\mathrm{CD}_{2} \mathrm{Cl}_{2}$ vs 63.0 to $70.6 \mathrm{~Hz}$ in $\mathrm{d}_{8}-\mathrm{THF}$ ). In contrast, dissolution of $3 e$ or $3 f$ in $d_{8}-\mathrm{THF}$ releases free $\mathrm{PPh}_{2} \mathrm{H}$ or $\mathrm{PCy}_{2} \mathrm{H}$ (see the Supporting Information).

We measured the UV-vis absorption spectra of $\mathbf{3 b} \mathbf{b} \mathbf{d}$ in THF (Figure 9), and we observed intense bands $(\varepsilon=6920-7910 \mathrm{~cm}$ $\left.{ }^{1} . \mathrm{M}^{-1}\right)$ in the blue region $(3 \mathrm{~b}->437 \mathrm{~nm} ; 3 \mathrm{c}->419 \mathrm{~nm}$; $3 \mathrm{~d}->448$ $\mathrm{nm})$.

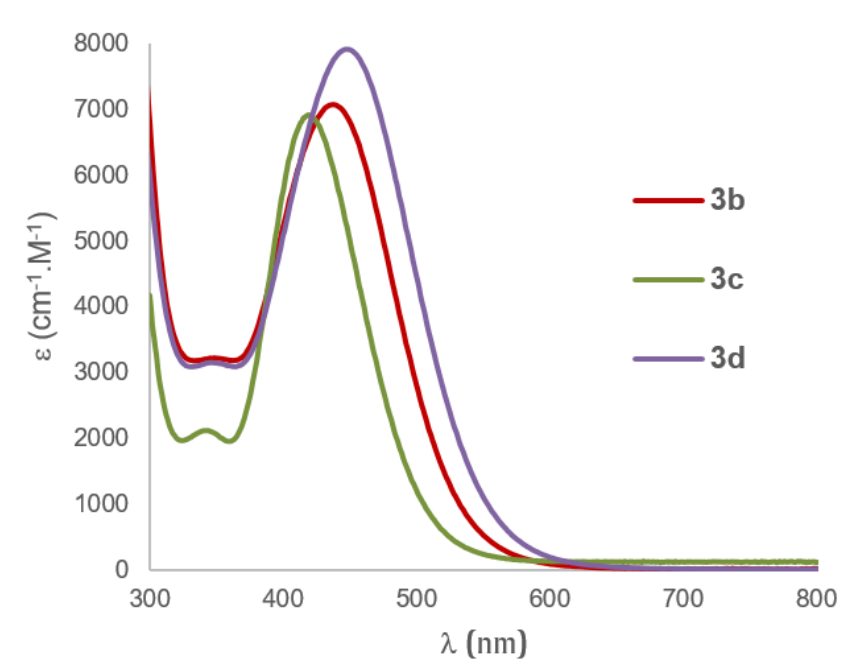

Figure 9. UV-vis spectra of $\mathbf{3 b}$-d in THF.

DFT calculations were conducted to investigate the nature of this transition. Natural Transition Orbitals (Figure 10) indicate that it corresponds to a LMCT band, mostly centred on the phosphido ligand. ${ }^{[30]}$

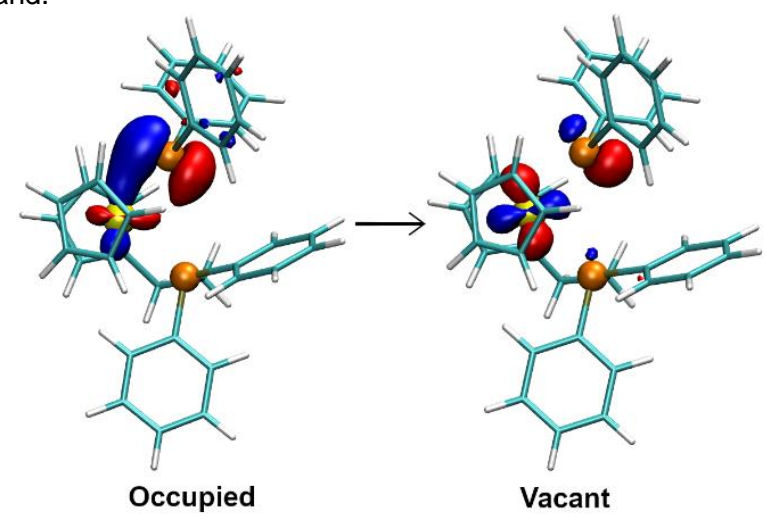

Figure 10. Natural Transition Orbitals for the highest energy UV-vis band of $\mathbf{3 b}$

Since $d^{0}$ phosphidotitanocene are usually unstable and readily decompose to give $\mathrm{Ti}(\mathrm{III})$ and phosphinyl radicals (Scheme 2), we were intrigued by the apparent stability of complexes $\mathbf{3 b} \mathbf{b} \mathbf{g}$. The presence of $\pi$ interactions between the $\mathrm{Cp}_{2} \mathrm{Ti}$ fragment and the phosphido ligand alone cannot explain this stability, as illustrated by our failure to prepare complex $\mathbf{3 e}$. We reasoned that the additional phosphane ligand in $\mathbf{3 b}-\mathbf{g}$ might simply provide kinetic stabilization to otherwise thermodynamically unstable entities. To test this hypothesis, we measured the EPR spectra of $\mathbf{3 b} \mathbf{b} \mathbf{g}$ and found that paramagnetic Ti-P species were present in every case. In the case of $\mathbf{3} \mathbf{f}$ and $\mathbf{3 g}$ we could positively identify the $\mathrm{Cp}_{2} \mathrm{Ti}(\mathrm{THF})_{2}{ }^{+}$cation as the main paramagnetic species $\left(\mathrm{g}=1.9758, \mathrm{~A}^{47 / 49 \mathrm{Ti}}=11.4 \times 10^{-4} \mathrm{~cm}^{-1}\right)$. For complexes $\mathbf{3 b}$-d, the spectra revealed the presence of at least three paramagnetic Ti-P species (see the Supporting Information).

Irradiation of $\mathbf{3 g}$ and $\mathbf{3 g}$ with a UV lamp for 20 minutes led to mixtures in which only the $\mathrm{Cp}_{2} \mathrm{Ti}(\mathrm{THF})_{2}{ }^{+}$cation was visible by EPR spectroscopy (Figure 11). 


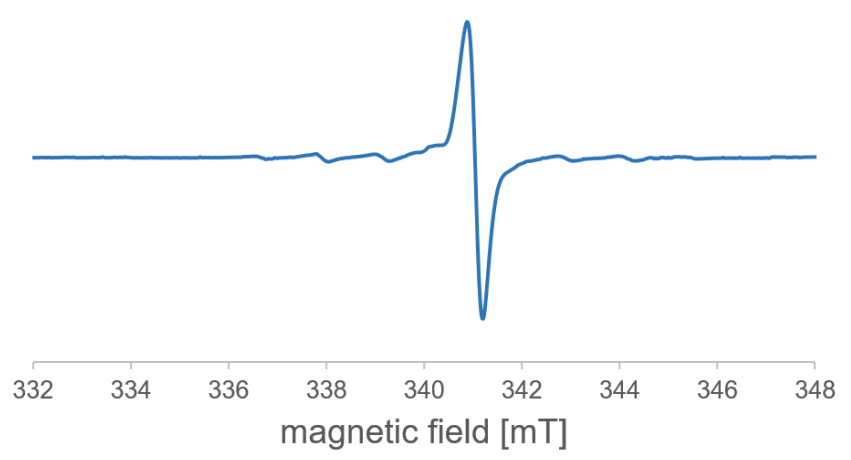

Figure 11. EPR spectrum of $\mathbf{3 g}$ after 20 min irradiation with a UV lamp

Analysis of the reaction mixtures by ${ }^{31} \mathrm{P}\left\{{ }^{1} \mathrm{H}\right\}$ and ${ }^{11} \mathrm{~B}\left\{{ }^{1} \mathrm{H}\right\}$ NMR spectroscopy revealed $i$ ) the complete disappearance of $\mathbf{3} \mathbf{f}$ and $\mathbf{3 g}$, ii) an intact $\mathrm{B}\left(\mathrm{C}_{6} \mathrm{~F}_{5}\right)_{4}$ anion, iii) concomitant formation of $\left(\mathrm{PPh}_{2}\right)_{2}$ for $\mathbf{3 g}$, and $\mathrm{iv}$ ) the apparition of several P-containing species in addition to $\mathrm{PCy}_{2} \mathrm{H}$ for $\mathbf{3 f}$ (some of which was present before irradiation) ${ }^{[31]}$

For complexes $\mathbf{3 b - d}$, the mixtures after UV irradiation were again complex by EPR spectroscopy, but in each case the $\mathrm{BPh}_{4}$ anion was also intact, whilst the presence of $\left(\mathrm{PPh}_{2}\right)_{2}(\mathbf{3 b}, \mathbf{3 d})$ or $\left(\mathrm{PCy}_{2}\right)_{2}(\mathbf{3 c})$ strongly suggested that $\mathrm{PR}_{2} \cdot$ radicals had been generated.

Therefore, it appears that $d^{0}$-phosphidotitanocene cations decompose by Ti-P bond homolysis just like their neutral counterparts. Compared to the unsubstituted complex $\mathbf{3 e}$, the additional stabilization provided by the phosphane ligand in $\mathbf{3 b} \mathbf{b} \mathbf{g}$ enables the isolation of these otherwise fleeting species.

In light of these findings, we decided to investigate whether complex $3 \mathbf{e}$ could be generated in situ and trapped with a suitable reagent. We had previously shown that the $Z r$ analogue of $\mathbf{3 e}(\mathbf{C} \mathbf{1})$ reacted with diphenylacetylene to give a $\mathrm{Zr}^{+} / \mathrm{P}$ frustrated Lewis pair (FLP), ${ }^{[7 a]}$ therefore we generated $3 \mathbf{e}$ in the presence of this reagent, and indeed complex $4 \mathrm{e}$ was isolated in $27 \%$ yield after workup (Scheme 8).
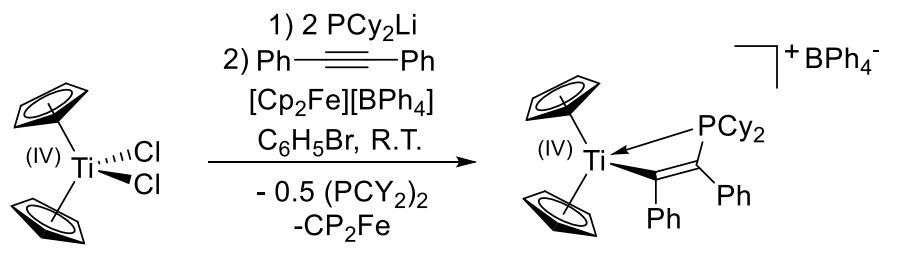

4e (483 mg, $27 \%$ )

Scheme 8. Synthesis of a $\mathrm{Ti}^{+} / \mathrm{P}$ FLP by the trapping of a phosphidotitanocene cation.

Evidence for the formation of $4 \mathrm{e}$ initially came from the comparison of its ${ }^{1} \mathrm{H}$ and ${ }^{31} \mathrm{P}\left\{{ }^{1} \mathrm{H}\right\}$ NMR spectra with those of the previously reported $\mathrm{Zr}$ analogue $\mathbf{E}$ (containing the $\mathrm{MeB}\left(\mathrm{C}_{6} \mathrm{~F}_{5}\right)_{3}$ anion). ${ }^{[7 a]}$ For example, the $\mathrm{Cp}$ hydrogens in $4 \mathbf{e}$ resonate as a doublet at $6.52 \mathrm{ppm}\left({ }^{3} \mathrm{JHH}_{\mathrm{PH}}=1.7 \mathrm{~Hz}\right)$ in $\mathrm{CD}_{2} \mathrm{Cl}_{2}$, indicative of phosphane coordination to $\mathrm{Ti}$, whilst the ${ }^{31} \mathrm{P}\left\{{ }^{1} \mathrm{H}\right\}$ spectrum shows a signal at $-7.6 \mathrm{ppm}$. Similar spectroscopic features were observed for compound E (Cp: $6.23 \mathrm{ppm},{ }^{3} \mathrm{JPH}_{\mathrm{PH}}=0.7 \mathrm{~Hz}$; phosphane : -12.4 ppm). ${ }^{[32]}$

Interestingly, the high-resolution ESI mass spectrum of $4 \mathbf{e}$ shows the expected presence of the $\mathrm{Cp}_{2} \mathrm{Ti}\left(\mathrm{C}(\mathrm{Ph}) \mathrm{C}(\mathrm{Ph}) \mathrm{PCy}_{2}{ }^{+}\right.$ cation (with a distinctive cluster of peaks at 553.24758 Da), but the elusive $\mathrm{Cp}_{2} \mathrm{Ti}(\mathrm{PCy})_{2}{ }^{+}$is also observed $(375.17211 \mathrm{Da})$. This suggests some degree of reversibility for the alkyne insertion reaction, at least under the relatively forcing conditions of the mass spectrometry experiment.

$\mathrm{APPh}_{2}$ analogue of $4 \mathrm{e}$ was also prepared by reacting $3 e$ with a four-fold excess of diphenylacetylene. Although the insertion reaction was much slower (72 $\mathrm{h}$ vs a few minutes), probably due to the necessity to dissociate $\mathrm{PPh}_{2} \mathrm{H}$ first, compound $4 \mathrm{e}$ (not shown) was isolated in $88 \%$ yield. The preparation of $4 \mathbf{e}$ starting from an isolated phosphidotitanocene cation indicates that alkyne insertion probably occurs after oxidation by $\left[\mathrm{Cp}_{2} \mathrm{Fe}\right]\left[\mathrm{BPh}_{4}\right]$ during the synthesis of $\mathbf{4 e}$.

Although $4 \mathbf{e}$ is stable enough to be isolated and characterized by NMR spectroscopy, UV-vis spectroscopy, ESI-MS and X-ray diffraction analysis (vide infra), it displays slightly broadened signals by ${ }^{1} \mathrm{H}$ NMR spectroscopy, suggesting the presence of paramagnetic impurities. Indeed, the EPR spectrum of a solution of $4 \mathbf{e}$ in $d_{8}$-THF indicated the presence of small amounts of $\left[\mathrm{Cp}_{2} \mathrm{Ti}(\mathrm{THF})_{2}\right]\left[\mathrm{BPh}_{4}\right]$ (see the Supporting Information), which again points to the reversible insertion of diphenylacetylene into the Ti-P bond of $3 \mathbf{e}$.

Irradiation of this solution with a UV lamp and monitoring the reaction by EPR spectroscopy revealed that a new Ti-P product was being formed in equimolar quantities with $\left[\mathrm{Cp}_{2} \mathrm{Ti}(\mathrm{THF})_{2}\right]\left[\mathrm{BPh}_{4}\right]$. Both ${ }^{1} \mathrm{H}$ and ${ }^{31} \mathrm{P}\left\{{ }^{1} \mathrm{H}\right\}$ spectra showed the complete disappearance of $4 \mathbf{e}$, although the ${ }^{11} \mathrm{~B}\left\{{ }^{1} \mathrm{H}\right\}$ NMR spectrum did not evolve during photolysis. Borates are known to decompose photolytically in the presence of electron acceptors, ${ }^{[3]}$ therefore we initially envisaged a non-innocent role for the $\mathrm{BPh}_{4}^{-}$anion. However, we could not find any evidence for the oxidation of $\mathrm{BPh}_{4}{ }^{-}$, nor could we identify the diamagnetic byproducts of the reaction.

The reaction was repeated on preparative scale, and complex $4 e^{\prime}$ was isolated in $40 \%$ yield after workup (Scheme 9 ).

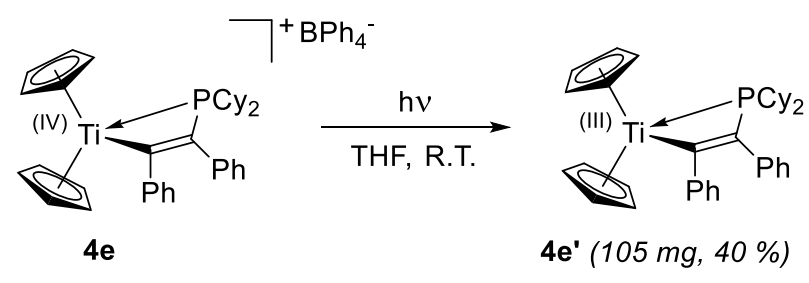

Scheme 9 . Synthesis of $4 \mathrm{e}$ by photolysis of $4 \mathrm{e}$.

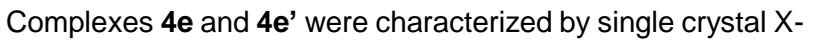
ray diffraction analysis (Figure 12, Table 5). The metric parameters of these complexes support their formulation as $\mathrm{Ti}$ alkenyl complexes with a chelating phosphane arm, rather than Ti-carbene complexes bound to an alkylidene phosphonium moiety. ${ }^{[34]}$ The C11-C12 bond distances are consistent with a

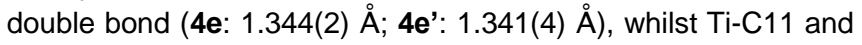
C12-P distances indicate the presence of single bonds (4e:

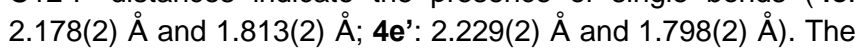


shorter Ti-P distance in $4 \mathrm{e}$ reflects the higher Lewis acidity of

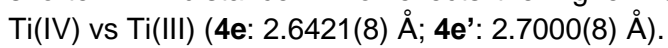
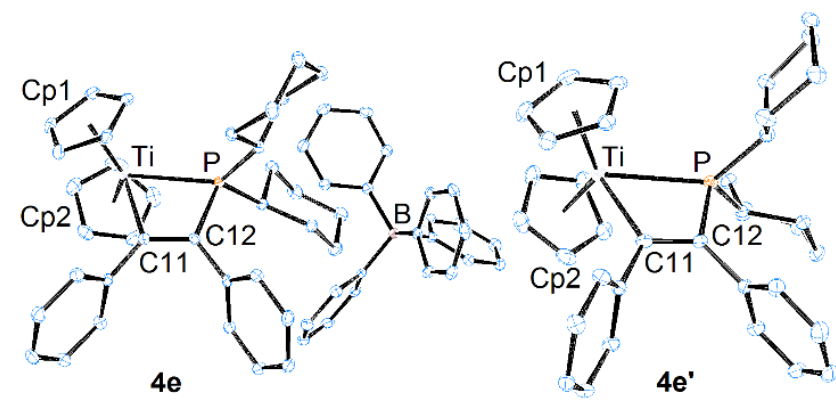

Figure 12. ORTEP drawings of the X-ray structures of $4 \mathbf{e}$ and $4 e^{\prime}$ (ellipsoids drawn at the $30 \%$ probability level, hydrogen atoms removed for clarity) $\mathrm{Cp} 1$ and $\mathrm{Cp} 2$ indicate the centroid of the $\mathrm{Cp}$ rings. Selected bond distances $(\AA)$ and angles $\left({ }^{\circ}\right) .4 \mathrm{e}: \mathrm{Ti}-\mathrm{Cp} 1=2.0347(9) ; \mathrm{Ti}-\mathrm{Cp} 2=2.0379(9) ; \mathrm{Ti}-\mathrm{P}=2.6421(8) ; \mathrm{Ti}-\mathrm{C} 11$ $=2.178(2) ; \mathrm{C} 11-\mathrm{C} 12=1.344(2) ; \mathrm{C} 12-\mathrm{P}=1.813(2) ; \mathrm{Cp} 1-\mathrm{Ti}-\mathrm{Cp} 2=133.83(4) ; \mathrm{P}-$ $\mathrm{Ti}-\mathrm{C} 11=63.37(4) ; \Sigma \alpha(\mathrm{C} 11)=359.8(2) ; \Sigma \alpha(\mathrm{C} 12)=359.7(2) .4 \mathrm{e}^{\prime}: \mathrm{Ti}-\mathrm{Cp} 1=$ 2.0562(13); Ti-Cp2 = 2.0623(13); Ti-P = 2.7000(8); Ti-C11 = 2.229(2); C11-C12 $=1.341(4) ; \mathrm{C} 12-\mathrm{P}=1.798(2) ; \mathrm{Cp} 1-\mathrm{Ti}-\mathrm{Cp} 2=133.46(6) ; \mathrm{P}-\mathrm{Ti}-\mathrm{C} 11=61.22(6)$; $\Sigma \alpha(\mathrm{C} 11)=359.6(3) ; \Sigma \alpha(\mathrm{C} 12)=359.9(3)$

In order to determine the redox properties of the $4 \mathbf{e} / \mathbf{4} \mathbf{e}^{\prime}$, couple, voltammetric analyses were performed in THF, with $0.1 \mathrm{M}$ $\mathrm{NaBPh}_{4}$ as electrolyte. Under these conditions, $4 \mathrm{e}$ is reversibly reduced at $E_{1 / 2}=-0.420 \mathrm{~V}$ vs. SCE (Figure 13). The reduced species was attributed to the Ti(III) complex $4 e^{\prime}$. Complementary cyclic and steady state voltammetry experiments conducted on a mixture of $4 \mathrm{e}$ and $4 \mathrm{e}^{\prime}$ confirmed that these compounds form one redox couple, and can be reversibly transformed into each other (see the supporting information).

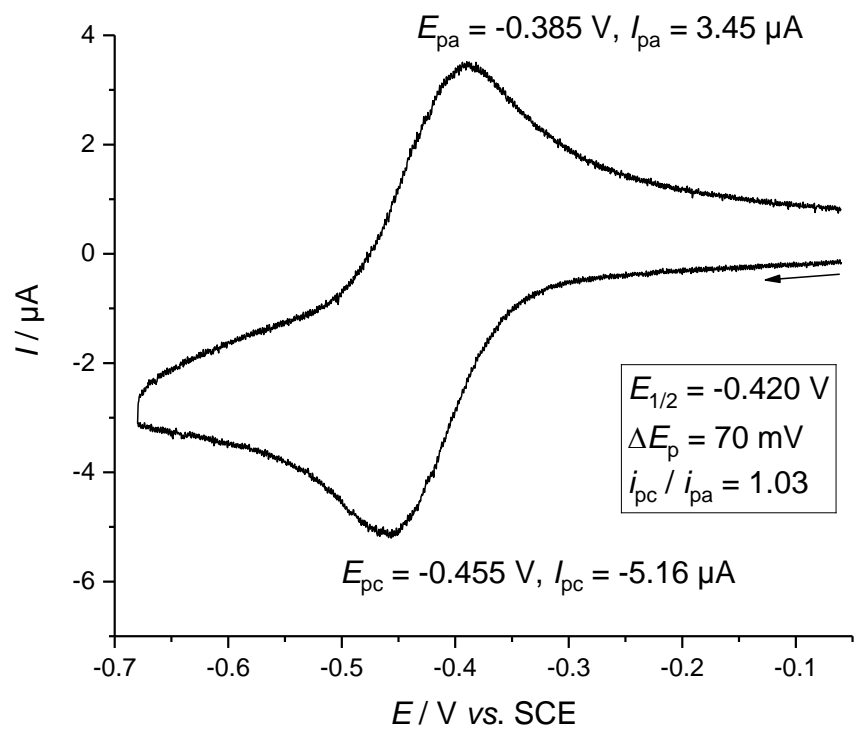

Figure 13. 4e in THF $0.1 \mathrm{M} \mathrm{NaBPh}_{4}\left([4 \mathrm{e}]=5 \times 10^{-4} \mathrm{M}, v=100 \mathrm{mV} \mathrm{s}^{-1}\right.$, working electrode: $\mathrm{GC}$ electrode $\varnothing=3 \mathrm{~mm}$, counter electrode: Pt, Reference electrode: SCE).

Finally, we investigated the FLP behaviour of $4 \mathbf{e}$. By contrast with the $\mathrm{Zr}$ analogue $\mathbf{E}$, reaction with chalcone or $1 \mathrm{~atm} \mathrm{CO}_{2}$ at room temperature in $\mathrm{CD}_{2} \mathrm{Cl}_{2}$ did not yield the expected FLP adducts: no reaction was observed in both cases. However, when $4 e$ was reacted with ferrocene carboxaldehyde in $\mathrm{CH}_{2} \mathrm{Cl}_{2}$, compound 5 e was obtained in $83 \%$ yield after workup (Scheme $10)$.

$4 e$
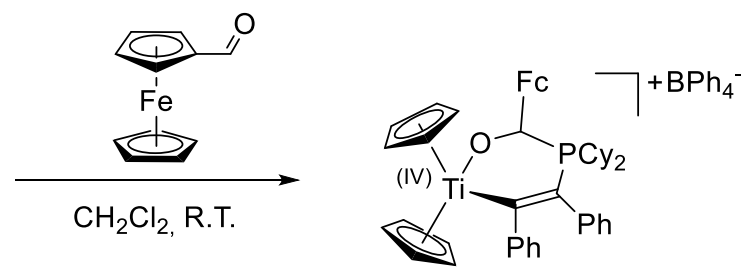

5e (176 mg, $83 \%)$

Scheme 10. FLP reaction of $4 \mathrm{e}$ with ferrocene carboxaldehyde.

Compound 5e exhibits characteristic NMR features in $\mathrm{CD}_{2} \mathrm{Cl}_{2}$, indicative of the activation of the $\mathrm{CHO}$ moiety by the Ti /P FLP. Firstly, the ${ }^{31} \mathrm{P}\left\{{ }^{1} \mathrm{H}\right\}$ NMR spectrum shows a signal at $32.5 \mathrm{ppm}(\mathbf{4 e}$ : $-7.6 \mathrm{ppm}$ ), consistent with the presence of a phosphonium moiety. Secondly, the activated aldehydic proton resonates as a broad signal at $6.12 \mathrm{ppm}$ in the ${ }^{1} \mathrm{H}$ spectrum, and couples both with the carbons of the ferrocene $\mathrm{Cp}$ ring and the $\mathrm{CH}$ carbons of the $\mathrm{Cy}$ rings in the HMBC spectrum. Finally, the activated aldehydic carbon resonates as a doublet at $80.2 \mathrm{ppm}\left({ }^{1} \mathrm{JPC}_{\mathrm{PC}}=49.2 \mathrm{~Hz}\right)$ in the ${ }^{13} \mathrm{C}\left\{{ }^{1} \mathrm{H}\right\}$ spectrum.

The high resolution ESI spectrum of $5 \mathbf{e}$ displays a single cluster of peaks at $767.25649 \mathrm{Da}$, which is again consistent with FLP adduct formation.

Single crystals suitable for $\mathrm{X}$-ray diffraction were obtained by slow diffusion of pentane into a $\mathrm{CH}_{2} \mathrm{Cl}_{2}$ solution of $5 \mathrm{e}$ at $-18{ }^{\circ} \mathrm{C}$ (Figure 14).

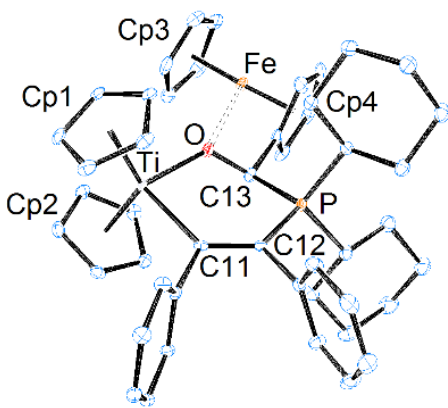

Figure 14. ORTEP drawings of the $\mathrm{X}$-ray structure of $\mathbf{5 e}$ (ellipsoids drawn at the $30 \%$ probability level, hydrogen atoms, $\mathrm{BPh}_{4}^{-}$anion and $\mathrm{CH}_{2} \mathrm{Cl}_{2}$ solvate molecules removed for clarity).

Compared to $\mathbf{4 e}$, the Ti-C11 distance $(2.231(3) \AA)$ is significantly elongated $(+0.053(4) \AA)$. The C11-C12 distance is somewhat elongated $(1.361(3) \AA,+0.017(4) \AA)$, whilst the C12-P distance is slightly shortened $(1.800(3) \AA$, $-0.013(4) \AA$ ). Noteworthy, the Fe-O distance $(3.521(2) \AA)$ is shorter than the sum of Van der Waals radii $(3.94 \AA)$, a feature which was previously observed in a related $\mathrm{Zr}$ complex. ${ }^{[35]}$

Finally, complex 4e' failed to react with ferrocene carboxaldehyde (toluene, room temperature), highlighting the 
greater Lewis acidity of the $d^{0}$ titanocenium cation compared to its neutral $d^{1}$ sibling.

\section{Conclusions}

Although $d^{0}$ phosphidotitanocene complexes are intrinsically unstable due to their redox-labile nature, we have shown that they can be isolated as phosphane-stabilized cations. This is somewhat counter-intuitive, since $d^{0}$ complexes are classified as hard Lewis acids, whilst phosphorus-based ligands fall in the category of soft Lewis bases. It appears that the phosphanestabilized phosphidotitanocene cations reported in this study are unique in many ways: although they are stable enough to be isolated and crystallographically characterized, they readily decompose in the presence of light. Additionally, they have strikingly similar structures in solution and in the solid state, a consequence of the pre-organization of the phosphanefunctionalized metallocenium fragment in a favourable conformation for $\mathrm{CH} / \pi$ interactions. Thus, in contrast to their redox-labile behaviour, they show great structural resilience even in coordinating solvents such as $d_{8}$-THF. Finally, they give rise to extremely high ${ }^{31} \mathrm{P}$ NMR chemical shifts, in the 400-500 ppm range, as a consequence of the double-bond character of the Ti$P$ interaction.

\section{Experimental Section}

\section{General}

General information, detailed reaction procedures, analytical details, and structural data of the new compounds are given in the Supporting Information.

\section{Synthesis}

Compound 2a: In an Ar glovebox, a solution of $\mathrm{PPh}_{2} \mathrm{Li}$ (408 mg, 2.0 $\mathrm{mmol})$ in THF $(6 \mathrm{~mL})$ was added to a suspension of complex $1 \mathrm{a}(487$ $\mathrm{mg}, 1.0 \mathrm{mmol})$ in THF $(8 \mathrm{~mL})$. The reaction mixture turned green almost instantly, and was stirred at room temperature for $30 \mathrm{~min}$. Volatiles were removed in vacuo outside the glovebox, and toluene $(15 \mathrm{~mL})$ was added to the residue. The resulting suspension was filtered over diatomaceous earth to remove $\mathrm{LiCl}$, and the filtrate was evaporated. The residue was taken inside the glovebox, and $\mathrm{Et}_{2} \mathrm{O}$ (15 $\mathrm{mL}$ ) was added, forming a green precipitate. It was filtered over a sintered glass frit, rinsed with $3 \times 10 \mathrm{~mL}$ of $\mathrm{Et}_{2} \mathrm{O}$, then $2 \times 10 \mathrm{~mL}$ of pentane, then dried on the frit, yielding $2 a$ as a green microcrystalline solid (374 mg, $62 \%$ ).

Single crystals suitable for $\mathrm{X}$-ray diffraction analysis were obtained by slow diffusion of pentane into a toluene solution of $2 \mathrm{a}$ at $-18^{\circ} \mathrm{C}$ Elemental Analysis: calcd for $\mathrm{C}_{37} \mathrm{H}_{47} \mathrm{P}_{2} \mathrm{Ti}: \mathrm{C}, 73.87 ; \mathrm{H}, 7.87$. Found: $\mathrm{C}$, 73.17; $\mathrm{H}, 7.71$.

Compound 2b: A solution of PPh $2 \mathrm{Li}(769 \mathrm{mg}, 4.0 \mathrm{mmol})$ in THF (40 $\mathrm{mL}$ ) was added to a solution of complex $\mathbf{1 b}(920 \mathrm{mg}, 2.0 \mathrm{mmol})$ in THF $(40 \mathrm{~mL})$. The reaction mixture turned green almost instantly, volatiles were removed in vacuo, and toluene $(30 \mathrm{~mL})$ was added to the residue. The resulting suspension was filtered over diatomaceous earth to remove $\mathrm{LiCl}$, and the filtrate was evaporated. The residue was taken inside the glovebox, and a mixture of $\mathrm{Et}_{2} \mathrm{O}(25 \mathrm{~mL})$ and pentane $(25 \mathrm{~mL})$ was added, forming a green precipitate. It was filtered over a sintered glass frit, rinsed with $3 \times 4 \mathrm{~mL}$ of a 1:1 mixture of $\mathrm{Et}_{2} \mathrm{O} /$ pentane, then dried on the frit, yielding $\mathbf{2 b}$ as a green powder $(770 \mathrm{mg}, 67 \%$ ). Single crystals suitable for X-ray diffraction analysis were obtained by slow diffusion of pentane into a toluene solution of $2 \mathrm{~b}$ at $-18^{\circ} \mathrm{C}$.
Elemental Analysis: a satisfactory elemental analysis could not be obtained for this compound despite repeated attempts ( $\mathrm{C}$ content was always low by $5-10 \%)$.

Compound 2c: In an Ar glovebox, a solution of $\mathrm{PCy}_{2} \mathrm{Li}(408 \mathrm{mg}, 2.0$ $\mathrm{mmol})$ in THF (6 mL) was added to a solution of complex 1c $(461 \mathrm{mg}$, $1.0 \mathrm{mmol})$ in THF $(6 \mathrm{~mL})$. The reaction mixture turned brown almost instantly, volatiles were removed in vacuo outside the glovebox, and toluene $(30 \mathrm{~mL})$ was added to the residue. The resulting suspension was taken back inside the glovebox, filtered over diatomaceous earth to remove $\mathrm{LiCl}$, and the filtrate was evaporated outside the glovebox. The residue was taken inside the glovebox and triturated in $\mathrm{Et}_{2} \mathrm{O}(20$ $\mathrm{mL}$ ), forming a brown precipitate. It was filtered over a sintered glass frit, rinsed with $3 \times 4 \mathrm{~mL}$ of a $1: 1$ mixture of $\mathrm{Et}_{2} \mathrm{O} /$ pentane, then dried on the frit, yielding $2 \mathrm{c}$ as a brown powder ( $325 \mathrm{mg}, 55 \%)$. Single crystals suitable for X-ray diffraction analysis were obtained by slow diffusion of pentane into a toluene solution of $2 \mathrm{c}$ at $-18^{\circ} \mathrm{C}$. Elemental Analysis: calcd for $\mathrm{C}_{36} \mathrm{H}_{45} \mathrm{P}_{2} \mathrm{Ti}$ : C, 73.59; $\mathrm{H}, 7.72$. Found: $\mathrm{C}, 73.40 ; \mathrm{H}, 7.60$.

Compound 2d: In an Ar glovebox, a solution of $\mathrm{PCy}_{2} \mathrm{Li}(408 \mathrm{mg}, 2.0$ $\mathrm{mmol})$ in THF (6 mL) was added to a solution of complex 1c $(461 \mathrm{mg}$, $1.0 \mathrm{mmol})$ in THF $(6 \mathrm{~mL})$. The reaction mixture turned green almost instantly, volatiles were removed in vacuo outside the glovebox, and toluene $(30 \mathrm{~mL})$ was added to the residue. The resulting suspension was taken back inside the glovebox, filtered over diatomaceous earth to remove $\mathrm{LiCl}$, and the filtrate was evaporated outside the glovebox. The residue was taken inside the glovebox and triturated in $\mathrm{Et}_{2} \mathrm{O}(20$ $\mathrm{mL}$ ), forming a green precipitate. It was filtered over a sintered glass frit, rinsed with $3 \times 4 \mathrm{~mL}$ of a 1:1 mixture of $\mathrm{Et}_{2} \mathrm{O} /$ pentane, then dried on the frit, yielding $2 \mathrm{~d}$ as a brown powder $(307 \mathrm{mg}, 52 \%)$. Single crystals suitable for X-ray diffraction analysis were obtained by slow diffusion of pentane into a toluene solution of $\mathbf{2} \mathbf{d}$ at $-18^{\circ} \mathrm{C}$. Elemental Analysis: calcd for $\mathrm{C}_{36} \mathrm{H}_{45} \mathrm{P}_{2} \mathrm{Ti}$ : C, 73.59; $\mathrm{H}, 7.72$. Found: $\mathrm{C}, 73.34 ; \mathrm{H}, 7.59$.

Compound 3b: In an Ar glovebox, 2b (574 mg, $1.0 \mathrm{mmol}$ ) and $\left[\mathrm{Cp}_{2} \mathrm{Fe}\right]\left[\mathrm{BPh}_{4}\right](505 \mathrm{mg}, 1.0 \mathrm{mmol})$ were mixed in $\mathrm{C}_{6} \mathrm{H}_{5} \mathrm{Br}(5 \mathrm{~mL})$. The reaction mixture gradually turned from green to red over $5 \mathrm{~min}$; residual particles of $\left[\mathrm{Cp}_{2} \mathrm{Fe}\right]\left[\mathrm{BPh}_{4}\right]$ were observed. After decantation, the supernatant was added to $50 \mathrm{~mL}$ of pentane under vigorous agitation. A brick-red solid formed, it was filtered over a sintered glass frit, suspended three times in pentane $(5 \mathrm{~mL})$ and dried on the frit. The resulting powder was freed from residual $\mathrm{C}_{6} \mathrm{H}_{5} \mathrm{Br}$ and $\left[\mathrm{Cp}_{2} \mathrm{Fe}\right]$ by dissolution in $\mathrm{CH}_{2} \mathrm{Cl}_{2}(4 \mathrm{~mL})$, filtration over diatomaceous earth, and precipitation as previously. Finally, the obtained product was stirred in toluene $(8 \mathrm{~mL})$ for $3 \mathrm{~h}$, then filtered and rinsed with toluene and pentane, yielding $\mathbf{3 b}$ as a brick-red powder containing $50 \mathrm{~mol} \%$ of toluene and $15 \mathrm{~mol} \%$ of pentane (708 $\mathrm{mg}, 79 \%)$. Single crystals suitable for $\mathrm{X}$-ray diffraction analysis were obtained by slow diffusion of pentane into $\mathrm{a} \mathrm{CH}_{2} \mathrm{Cl}_{2}$ solution of $3 \mathbf{b}$ at $-18^{\circ} \mathrm{C}$. Elemental Analysis: calcd for $\mathrm{C}_{60} \mathrm{H}_{53} \mathrm{BP}_{2} \mathrm{Ti}\left(\mathrm{C}_{7} \mathrm{H}_{8}\right)_{0.5}\left(\mathrm{C}_{5} \mathrm{H}_{12}\right)_{0.15}: \mathrm{C}, 81.10 ; \mathrm{H}, 6.23$. Found: $\mathrm{C}$, 79.88; H, 6.04

Compound 3c: In an Ar glovebox, 2c (196 mg, $0.33 \mathrm{mmol})$ and $\left[\mathrm{Cp}_{2} \mathrm{Fe}\right]\left[\mathrm{BPh}_{4}\right]$ (168 mg, $\left.0 \mathrm{mmol}\right)$ were mixed in $\mathrm{C}_{6} \mathrm{H}_{5} \mathrm{Br}(5 \mathrm{~mL})$. The reaction mixture gradually turned from green to red over $5 \mathrm{~min}$; residual particles of $\left[\mathrm{Cp}_{2} \mathrm{Fe}\right]\left[\mathrm{BPh}_{4}\right]$ were observed, hence the mixture was filtered over diatomaceous earth. The resulting solution was added to $100 \mathrm{~mL}$ of pentane under vigorous agitation. An orange solid formed, it was filtered over a sintered glass frit, suspended three times in pentane $(5 \mathrm{~mL})$ and dried on the frit. The resulting powder was freed from residual $\mathrm{C}_{6} \mathrm{H}_{5} \mathrm{Br}$ and $\mathrm{Cp}_{2} \mathrm{Fe}$ by stirring in toluene $(20 \mathrm{~mL})$. An oil formed initially, which turned into a powder over $10 \mathrm{~min}$. The solid was filtered over a sintered glass frit, suspended three times in toluene ( 4 $\mathrm{mL}$ ) then three times in pentane $(4 \mathrm{~mL})$ and dried on the fritt. Complex $3 \mathrm{c}$ was obtained as an orange powder containing $66 \mathrm{~mol} \%$ of toluene $(178 \mathrm{mg}, 59 \%)$. Single crystals suitable for $\mathrm{X}$-ray diffraction analysis were obtained by slow diffusion of pentane into a $\mathrm{CH}_{2} \mathrm{Cl}_{2}$ solution of $3 \mathbf{c}$ at $-18^{\circ} \mathrm{C}$. Elemental Analysis: calcd for $\mathrm{C}_{60} \mathrm{H}_{64} \mathrm{BP}_{2} \mathrm{Ti}\left(\mathrm{C}_{7} \mathrm{H}_{8}\right)_{0.66}$ : $\mathrm{C}$, 80.30; H, 7.22. Found: C, 79.40; H, 7.17.

Compound 3d: In an Ar glovebox, 2d (218 mg, $0.37 \mathrm{mmol})$ and $\left[\mathrm{Cp}_{2} \mathrm{Fe}\right]\left[\mathrm{BPh}_{4}\right]$ (188 mg, $0.37 \mathrm{mmol}$ ) were mixed in $\mathrm{C}_{6} \mathrm{H}_{5} \mathrm{Br}(3 \mathrm{~mL})$. The reaction mixture gradually turned from green to red over $5 \mathrm{~min}$; 
residual particles of $\left[\mathrm{Cp}_{2} \mathrm{Fe}\right]\left[\mathrm{BPh}_{4}\right]$ were observed, hence the mixture was filtered over diatomaceous earth. The resulting solution was added to $100 \mathrm{~mL}$ of pentane under vigorous agitation. A brick-red solid formed, it was filtered over a sintered glass frit, suspended three times in pentane $(10 \mathrm{~mL})$ and dried on the frit. The resulting powder was freed from residual $\mathrm{C}_{6} \mathrm{H}_{5} \mathrm{Br}$ and $\mathrm{Cp}_{2} \mathrm{Fe}$ by stirring in toluene $(10 \mathrm{~mL})$. An oil formed, the supernatant was discarded, fresh toluene $(10 \mathrm{~mL})$ was added and agitation was resumed. A powder formed over a few hours. The solid was filtered over a sintered glass frit, suspended three times in toluene $(6 \mathrm{~mL})$ then three times in pentane $(10 \mathrm{~mL})$ and dried on the frit. Complex $\mathbf{3 d}(178 \mathrm{mg}, 50 \%)$ was obtained as an orange powder.. Elemental Analysis: $\mathrm{C}_{60} \mathrm{H}_{64} \mathrm{BP}_{2} \mathrm{Ti}: \mathrm{C}, 79.56 ; \mathrm{H}, 7.12$. Found: C, 78.11; $\mathrm{H}, 7.32$.

Attempted synthesis of $3 \mathrm{e}: \mathrm{In}$ an $\mathrm{Ar}$ glovebox, $\mathrm{Cp}_{2} \mathrm{TiCl}_{2}(49.8 \mathrm{mg}$, $0.2 \mathrm{mmol})$ and $\mathrm{PCy}_{2} \mathrm{Li}(81.6 \mathrm{mg}, 0.4 \mathrm{mmol})$ were mixed in $\mathrm{C}_{6} \mathrm{H}_{5} \mathrm{Br}(2$ $\mathrm{mL}$ ). The mixture turned chocolate brown over $5 \mathrm{~min}$. It was filtered over diatomaceous earth, then $\left[\mathrm{Cp}_{2} \mathrm{Fe}\right]\left[\mathrm{BPh}_{4}\right](101 \mathrm{mg}, 0.2 \mathrm{mmol})$ was added and the resulting mixture was stirred for $5 \mathrm{~min}$, during which it turned progressively red. It was filtered over diatomaceous earth in order to remove a green-black insoluble solid. The homogeneous red filtrate was added to $80 \mathrm{~mL}$ of pentane under vigorous agitation, to precipitate an orange solid. The precipitate was filtered over a sintered glass frit, suspended three times in pentane $(10 \mathrm{~mL})$ and dried on the frit. An orange powder $(30 \mathrm{mg})$ was isolated and analyzed by NMR and EPR spectroscopy.

The ${ }^{1} \mathrm{H}$ and ${ }^{31} \mathrm{P}\left\{{ }^{1} \mathrm{H}\right\}$ NMR spectrum suggested the presence of the $\mathrm{Cp}_{2} \mathrm{Ti}\left(\mathrm{PCy}_{2}\right)\left(\mathrm{PCy}_{2} \mathrm{H}\right)^{+}$cation (compare with 3f) but impurities were also observed. Moreover the ${ }^{1} \mathrm{H}$ spectrum showed considerably broadened signals, consistent with the presence of paramagnetic impurities. The EPR spectrum revealed a mixture of species.

Compound 3f: In an Ar glovebox, $\mathrm{Cp}_{2} \mathrm{TiMe}_{2}(200 \mathrm{mg}, 0.96 \mathrm{mmol})$ and $\mathrm{Ph}_{3} \mathrm{CB}\left(\mathrm{C}_{6} \mathrm{~F}_{5}\right)_{4}$ (888 mg, $0.96 \mathrm{mmol}, 1$ eq) were mixed for $5 \mathrm{~min}$ in 2 $\mathrm{mL}$ of $\mathrm{C}_{6} \mathrm{H}_{5} \mathrm{Br}$ at room temperature. A solution of $\mathrm{PCy} \mathrm{H}_{2} \mathrm{H}(401 \mathrm{mg}, 2.02$ $\mathrm{mmol}$ ) in $\mathrm{C}_{6} \mathrm{H}_{5} \mathrm{Br}$ was added dropwise to the reaction mixture. The resulting deep-red solution was stirred for $3 \mathrm{~h}$ until a red precipitate was formed. The suspension was added dropwise to $8 \mathrm{~mL}$ of pentane under vigorous agitation to complete the precipitation of the desired red compound. The supernatant was removed and the red precipitate was washed twice with $5 \mathrm{~mL}$ of pentane. After removal of traces of pentane in vacuo, the red precipitate was dissolved in $\mathrm{CH}_{2} \mathrm{Cl}_{2}$ and precipitated from pentane as described above (N.B.: compound $\mathbf{3} f$ slowly decomposes in $\mathrm{CH}_{2} \mathrm{Cl}_{2}$, therefore this step must be performed quickly). Removal of volatiles in vacuo yielded complex $3 \mathbf{f}(1.20 \mathrm{~g}$, $83 \%$ ) as a red powder containing $50 \mathrm{~mol} \%$ of pentane. Elemental Analysis: calcd for $\mathrm{C}_{58} \mathrm{H}_{55} \mathrm{BF}_{20} \mathrm{P}_{2} \mathrm{Ti}\left(\mathrm{C}_{5} \mathrm{H}_{12}\right)_{0.5}$ : C, 56.39; $\mathrm{H}, 4.77$; Found: C, $57.00 ; \mathrm{H}, 5.00$.

Compound 3g: In an Ar glovebox, $\mathrm{Cp}_{2} \mathrm{TiMe}_{2}(200 \mathrm{mg}, 0.96 \mathrm{mmol})$ and $\left[\mathrm{Ph}_{3} \mathrm{C}\right]\left[\mathrm{B}\left(\mathrm{C}_{6} \mathrm{~F}_{5}\right)_{4}\right](888 \mathrm{mg}, 0.96 \mathrm{mmol}, 1 \mathrm{eq})$ were mixed for $5 \mathrm{~min}$ in $2 \mathrm{~mL}$ of $\mathrm{C}_{6} \mathrm{H}_{5} \mathrm{Br}$ at room temperature. A solution of $\mathrm{PPh}_{2} \mathrm{H}(376 \mathrm{mg}$, $2.02 \mathrm{mmol}$ ) in $\mathrm{C}_{6} \mathrm{H}_{5} \mathrm{Br}$ was added dropwise to the reaction mixture. The resulting deep-red solution was stirred for $3 \mathrm{~h}$ until a red precipitate was formed. The suspension was added dropwise to $8 \mathrm{~mL}$ of pentane under vigorous agitation to complete the precipitation of the desired red compound. The supernatant was removed and the red precipitate was washed twice with $5 \mathrm{~mL}$ of pentane. After removal of traces of pentane in vacuo, the red precipitate was dissolved in $\mathrm{CH}_{2} \mathrm{Cl}_{2}$ and precipitated from pentane as described above (N.B.: compound $3 g$ slowly decomposes in $\mathrm{CH}_{2} \mathrm{Cl}_{2}$, therefore this step must be performed quickly). Removal of volatiles in vacuo yielded complex $\mathbf{3 g}$ (980 mg, $83 \%$ ) as a red powder. Single crystals suitable for X-ray diffraction analysis were obtained by slow diffusion of heptane in a bromobenzene solution of the compound at $-18^{\circ} \mathrm{C}$. Elemental Analysis: calcd for $\mathrm{C}_{58} \mathrm{H}_{31} \mathrm{BF}_{20} \mathrm{P}_{2} \mathrm{Ti}$ : C, 57.07; $\mathrm{H}, 2.45$; Found: C, 56.71; $\mathrm{H}, 2.54$.

Compound $\left[\mathrm{Cp}_{2} \mathrm{Ti}(\mathrm{THF})_{2}\right]\left[\mathrm{BPh}_{4}\right]$ : In an $\mathrm{Ar}$ glovebox, $\mathrm{Cp}_{2} \mathrm{TiCl}_{2}(249$ $\mathrm{mg}, 1.0 \mathrm{mmol}$ ) and $\mathrm{PCy}_{2} \mathrm{Li}(408 \mathrm{mg}, 2.0 \mathrm{mmol}$ ) were mixed in toluene $(5 \mathrm{~mL})$. After $5 \mathrm{~min}$, the brown reaction mixture was filtered through diatomaceous earth and the filtrate was evaporated in vacuo outside of the glovebox. The residue was dissolved in THF $(10 \mathrm{~mL})$ in the glovebox, and $\left[\mathrm{Cp}_{2} \mathrm{Fe}\right]\left[\mathrm{BPh}_{4}\right](485 \mathrm{mg}, 0.9 \mathrm{mmol})$ was added. A blue precipitate appeared gradually; the presence of $\left(\mathrm{PCy}_{2}\right)_{2}$ was ascertained by performing no lock ${ }^{31} \mathrm{P}\left\{{ }^{1} \mathrm{H}\right\}$ NMR experiment. After $1 \mathrm{H}$ reaction, the reaction mixture was filtered over a sintered glass frit, the precipitate was suspended twice in THF $(1.5 \mathrm{~mL})$ and twice in pentane $(3.0 \mathrm{~mL})$ and dried on the frit. Complex $\left[\mathrm{Cp}_{2} \mathrm{Ti}(\mathrm{THF})_{2}\right]\left[\mathrm{BPh}_{4}\right]$ was obtained as a blue-green powder $(327 \mathrm{mg}, 51 \%)$. Material suitable for elemental analysis was obtained by diffusion of pentane into a THF solution $(50 \mathrm{~mL}$ ) of the crude product. Royal blue crystals of $\left[\mathrm{Cp}_{2} \mathrm{Ti}(\mathrm{THF})_{2}\right]\left[\mathrm{BPh}_{4}\right]$ were obtained $(152 \mathrm{mg}, 45 \%)$. Single crystals suitable for X-ray diffraction analysis were obtained by cooling a saturated solution of $\left[\mathrm{Cp}_{2} \mathrm{Ti}(\mathrm{THF})_{2}\right]\left[\mathrm{BPh}_{4}\right]$ in $\mathrm{THF}$ at $-18^{\circ} \mathrm{C}$. Elemental Analysis: calcd for $\mathrm{C}_{36} \mathrm{H}_{42} \mathrm{PTi}$ : C, 78.64; $\mathrm{H}, 7.23$. Found: $\mathrm{C}, 77.45 ; \mathrm{H}$, 7.11

Compound 4e: In an Ar glovebox, $\mathrm{Cp}_{2} \mathrm{TiCl}_{2}(498 \mathrm{mg}, 2.0 \mathrm{mmol})$ and $\mathrm{PCy}_{2} \mathrm{Li}(816 \mathrm{mg}, 4.0 \mathrm{mmol})$ were mixed in $\mathrm{C}_{6} \mathrm{H}_{5} \mathrm{Br}(8 \mathrm{~mL})$. After $5 \mathrm{~min}$, the brown reaction mixture was filtered through diatomaceous earth onto a mixture of $\left[\mathrm{Cp}_{2} \mathrm{Fe}\right]\left[\mathrm{BPh}_{4}\right](1.01 \mathrm{mg}, 2.0 \mathrm{mmol})$ and diphenylacetylene $(356 \mathrm{mg}, 2.0 \mathrm{mmol})$. A green-brown solution was obtained after $5 \mathrm{~min}$, which was added to $120 \mathrm{~mL}$ of pentane under vigorous agitation. A green solid formed, it was filtered over a sintered glass frit, suspended three times in pentane $(10 \mathrm{~mL})$ and dried on the frit. The resulting powder was freed from residual $\mathrm{C}_{6} \mathrm{H}_{5} \mathrm{Br}$ and $\mathrm{Cp}_{2} \mathrm{Fe}$ by dissolution in $\mathrm{CH}_{2} \mathrm{Cl}_{2}(6 \mathrm{~mL})$ and filtration over diatomaceous earth A blue-green solid was removed, and the resulting homogeneous solution was evaporated to dryness. Toluene $(100 \mathrm{~mL})$ was added to the residue, and a green solid formed. The suspension was stirred for $3 \mathrm{~h}$, then filtered over a sintered glass frit. The solid was suspended three times in toluene $(15 \mathrm{~mL})$ and three times in pentane $(15 \mathrm{~mL})$ and dried on the frit. Complex $4 \mathrm{e}$ was obtained as an olive green powder containing $40 \mathrm{~mol} \%$ of toluene $(483 \mathrm{mg}, 27 \%)$. Complex $4 e$ slowly degrades over time to give 4e' (vide infra), which explains the impossibility to obtain a satisfactory elemental analysis despite repeated attempts on different batches. Single crystals suitable for Xray diffraction analysis were obtained by slow diffusion of pentane into a $\mathrm{CH}_{2} \mathrm{Cl}_{2}$ solution of $4 \mathbf{e}$ at $-18^{\circ} \mathrm{C}$.

Compound 4e': A solution of $4 \mathrm{e}(440 \mathrm{mg}, 0.48 \mathrm{mmol})$ in THF $(15 \mathrm{~mL})$ was irradiated for $4 \mathrm{~h} 30$ with a 150 W UV lamp (Heraeus TQ 150) Volatiles were removed in vacuo and the residue was stirred in $20 \mathrm{~mL}$ of pentane inside an Ar glovebox for several hours. The resulting suspension was filtered on a sintered glass frit, yielding a blue-green solid and a brown solution. The solution was evaporated to dryness, yielding $4 \mathrm{e}^{\prime}$ as a brown gum (105 mg, $40 \%$ ). Single crystals suitable for X-ray diffraction analysis were obtained by cooling a saturated solution of $4 e^{\prime}$ in pentane at $-18^{\circ} \mathrm{C}$. Elemental Analysis: calcd for $\mathrm{C}_{36} \mathrm{H}_{42} \mathrm{PTi}$ : C, 78.11; $\mathrm{H}, 7.65$. Found: C, 77.27; H, 8.15.

Compound 4g: In an Ar glovebox, compound 3g (400 mg, 0.32 mmol) was dissolved in $\mathrm{C}_{6} \mathrm{H}_{5} \mathrm{Br}(3 \mathrm{~mL})$ with an excess of diphenylacetylene $(232 \mathrm{mg}, 1.3 \mathrm{mmol}$ ) at room temperature and stirred for $72 \mathrm{~h}$. The evolution of the reaction was followed by ${ }^{31} \mathrm{P}\left\{{ }^{1} \mathrm{H}\right\}$ no lock NMR experiments. The starting red solution became green. The compound was precipitated by addition to $6 \mathrm{~mL}$ of pentane under vigorous agitation. An oil formed, the supernatant was discarded and the oil extracted twice with pentane. The black-green residue was dissolved in $2 \mathrm{~mL}$ of dichloromethane and precipitated as described above. Compound $\mathbf{4 g}$ was obtained as a light brown powder containing $30 \mathrm{~mol} \%$ of pentane after drying in vacuo $(350 \mathrm{mg}, 88 \%$ ). Elemental Analysis: calcd for $\mathrm{C}_{60} \mathrm{H}_{30} \mathrm{BF}_{20} \mathrm{PTi}\left(\mathrm{C}_{5} \mathrm{H}_{12}\right)_{0.3}$ : C, 59.47; $\mathrm{H}$ 2.73; Found: C, 59.73; H, 2.44.

Compound 5e: In an Ar glovebox, compound 4e (170 mg, $0.19 \mathrm{mmol}$ ) and ferrocene carboxaldehyde $(42 \mathrm{mg}, 0.20 \mathrm{mmol})$ were mixed in $\mathrm{CH}_{2} \mathrm{Cl}_{2}(3 \mathrm{~mL}$ ). After $5 \mathrm{~min}$, the red reaction mixture was added to 50 $\mathrm{mL}$ of pentane under vigorous agitation. A red precipitate formed, which was filtered over a sintered glass frit, rinsed with pentane and dried under vacuum. Compoung $\mathbf{5 e}$ was obtained as a brown-red solid (176 mg, $83 \%$ ) containing $75 \mathrm{~mol} \%$ of pentane Single crystals suitable for $\mathrm{X}$-ray diffraction analysis were obtained by slow diffusion of pentane into $\mathrm{a} \mathrm{CH}_{2} \mathrm{Cl}_{2}$ solution of $5 \mathrm{e}$ at $-18^{\circ} \mathrm{C}$. Elemental Analysis: 
calcd for $\mathrm{C}_{71} \mathrm{H}_{72} \mathrm{BFeOPTi}\left(\mathrm{C}_{5} \mathrm{H}_{12}\right)_{0.75}: \mathrm{C}, 78.69 ; \mathrm{H}, 7.16$; Found: $\mathrm{C}$ 77.88; $\mathrm{H}, 6.74$

\section{Hydrolysis of $\mathrm{Ti}(\mathrm{III})-\mathrm{PPh}_{2}$ complexes}

In an Ar glovebox, the Ti(III)-PPh 2 complexes (2a: $0.5 \mathrm{mmol} ; \mathbf{2 b}: 0.19$ $\mathrm{mmol}$ ) were dissolved in $4 \mathrm{~mL}$ of THF and treated with 0.5 eq of distilled water in THF. The solution turned blue-violet immediately. The volatiles were removed in vacuo, the solid residue was triturated with pentane, filtered and rinsed with pentane. Blue violet powders were obtained in both cases after drying in vacuo (2a: $60 \mathrm{mg} ; 2 \mathrm{~b}$ : 46 $\mathrm{mg}$ ). EPR spectra of $\mathbf{2 a}$ and $\mathbf{2} \mathbf{b}$ were also recorded in "wet", unstabilized THF (degassed by free-pump-thaw) for comparison purposes.

\section{UV irradiation of $\mathrm{Ti}(\mathrm{IV})$ complexes}

The $\mathrm{Ti}^{(\mathrm{IV})}$ complexes (3b, 4e: $0.05 \mathrm{mmol}$; $\mathbf{3 c}-\mathbf{g}$ : $\left.0.01 \mathrm{mmol}\right)$ were dissolved in THF or $\mathrm{d}_{8}$-THF and irradiated in sequences of 20 min with a medium pressure Hg lamp (Heraeus TQ 150).

\section{FLP reactions}

Compound $4 \mathrm{e}(43.6 \mathrm{mg}, 0.05 \mathrm{mmol})$ was dissolved in $\mathrm{CD}_{2} \mathrm{Cl}_{2}$ Chalcone (10.4 mg, $0.05 \mathrm{mmol}$ ) was added and ${ }^{1} \mathrm{H}$ and ${ }^{31} \mathrm{P}\left\{{ }^{1} \mathrm{H}\right\}$ NMR spectra were recorded, showing only the presence of both reagents.

Compound $4 \mathrm{e}$ (43.6 mg, $0.05 \mathrm{mmol}$ ) was dissolved in $\mathrm{CD}_{2} \mathrm{Cl}_{2}$ and placed in a Schlenk vessel. The vessel was quickly evacuated, and refilled with $1 \mathrm{~atm}$ of $\mathrm{CO}_{2}$. The reaction mixture was stirred for $2 \mathrm{~h}$, and ${ }^{1} \mathrm{H}$ and ${ }^{31} \mathrm{P}\left\{{ }^{1} \mathrm{H}\right\}$ NMR spectra were recorded, showing only the presence of $4 \mathrm{e}$.

Compound 4e' (55.4 mg, $0.1 \mathrm{mmol})$ was dissolved in toluene. Ferrocene carboxaldehyde $(21.4 \mathrm{mg}, 0.1 \mathrm{mmol}$ ) was added and an EPR spectrum was recorded, showing only the presence of $4 \mathbf{e}^{\prime}$

\section{Computational details}

All DFT and TD-DFT calculations were carried out with the Gaussian09 code, ${ }^{[36]}$ tightening self-consistent field convergence thresholds $\left(10^{-10}\right.$ a.u. $)$. Geometries were optimized using the B3PW91 functional, with the def2-TZVP basis set for the titanium and the 6$31+G(d, p)$ basis set for other atoms. ${ }^{[37]}$ Vertical excitations were computed with TD-DFT using the B3PW91 functional, with the def2TZVP basis set for the titanium and the $6-311++G(d, p)$ basis set for other atoms. For each complex, 8 states were considered. The solvent effects of THF were included according to the Polarizable Continuum Model (PCM) ${ }^{[38]}$ All orbital isosurfaces have been plotted with the VMD code. ${ }^{[39]}$ The orbital transitions of selected excited states were characterized using the natural transition orbital (NTO) method. ${ }^{[40]}$

Following the benchmark calculations of Hadt et al. ${ }^{[41]}$ and our previous work, ${ }^{[42]}$ EPR g parameters were computed using the GGA BPW91 functional with the aug-cc-pVTZ-J basis set for the Ti atom, ${ }^{[43]}$ and the IGLO-III basis set for other atoms ${ }^{[44]}$ The A parameters were computed using the hybrid B3LYP functional with the same basis sets. The aug-cc-pVTZ-J basis sets were taken from the EMSL Basis Set Exchange Web site. ${ }^{[45]}$ All parameters were computed in toluene modelled as a PCM.

\section{Acknowledgements}

We thank Dr Jean-Claude Chambron and Dr Yves Canac for stimulating discussions on $\mathrm{CH}--\pi$ interactions and recordbreaking ${ }^{31} \mathrm{P}$ NMR shifts in group 4 metal phosphides, respectively. We thank Dr Michel Meyer for the use of his UV-vis spectrometer. We thank Ms. Marie-José Penouilh-Suzette for measuring the HRMS spectra. Financial support from the Centre National de la Recherche Scientifique (CNRS), Agence Nationale de la Recherche, Deutsche Forschungsgemeinschaft (MENOLEP project), the Conseil Regional de Bourgogne (PARI CDEA program), and the Fonds Européen de Développement Régional (FEDER) is gratefully acknowledged.

Keywords: transition metal phosphides $\cdot$ titanium $\cdot$ phosphorus ligands $\cdot$ FLP $\cdot$ DFT

[1] a) K. Issleib and E. Wenschuh, Chem. Ber. 1964, 97, 715-720; b) K. Issleib and H. Häckert, Z. Naturforsch. B 1966, 21, 519-521.

[2] For reviews, see : a) E. Hey-Hawkins, Chem. Rev. 1994, 94, 1661 1717; b) D. W. Stephan, Angew. Chem. Int. Ed. 2000, 39, 314-329; c) R. Waterman, Dalton Trans. 2009, 18-26; d) L. Rosenberg, Coord. Chem. Rev. 2012, 256, 606-626.

[3] See refs 1, 2 and a) K. Issleib, G. Wille and F. Krech, Angew. Chem. 1972, 84, 582-582; b) R. T. Baker, P. J. Krusic, T. H. Tulip, J. C Calabrese and S. S. Wreford, J. Am. Chem. Soc. 1983, 105, 6763 $6765 ;$ c) R. T. Baker, J. F. Whitney and S. S. Wreford, Organometallics 1983, 2, 1049-1051; d) S. R. Wade, M. G. H Wallbridge and G. R. Willey, J. Chem. Soc. Dalton Trans. 1983, 2555 2559; e) E. Hey-Hawkins and S. Kurz, J. Organomet. Chem. 1994 479, 125-133; f) E. Hey-Hawkins, S. Kurz, J. Sieler and G. Baum, J. Organomet. Chem. 1995, 486, 229-235; g) C. Frenzel, E. HeyHawkins, U. Müller and I. Strenger, Zeit. Anorg. Allg. Chem. 1997, 623, 277-280; h) S. Xin, H. G. Woo, J. F. Harrod, E. Samuel and A.-M. Lebuis, J. Am. Chem. Soc. 1997, 119, 5307-5313; i) U. Segerer and E. Hey-Hawkins, Polyhedron 1997, 16, 2537-2545; j) U. Segerer, S. Blaurock, J. Sieler and E. Hey-Hawkins, Organometallics 1999, 18 2838-2842; k) T. Koch, S. Blaurock, F. B. Somoza, A. Voigt, R. Kirmse and E. Hey-Hawkins, Organometallics 2000, 19, 2556-2563; I) U. Segerer, S. Blaurock, J. Sieler and E. Hey-Hawkins, J. Organomet. Chem. 2000, 608, 21-26; m) E. Urnezius, S. J. Klippenstein and J. D. Protasiewicz, Inorg. Chim. Act. 2000, 297, 181-190; n) G. Altenhoff, S. Bredeau, G. Erker, G. Kehr, O. Kataeva and R. Fröhlich, Organometallics 2002, 21, 4084-4089; o) S. Bredeau, G. Altenhoff, K. Kunz, S. Döring, S. Grimme, G. Kehr and G. Erker, Organometallics 2004, 23, 1836-1844; p) A. J. Roering, S. N. MacMillan, J. M. Tanski and R. Waterman, Inorg. Chem. 2007, 46, 6855-6857; q) U. J. Kilgore, H. Fan, M. Pink, E. Urnezius, J. D. Protasiewicz and D. J. Mindiola Chem. Commun. 2009, 4521-4523; r) A. J. Roering, A. F. Maddox, L. T. Elrod, S. M. Chan, M. B. Ghebreab, K. L. Donovan, J. J. Davidson, R. P. Hughes, T. Shalumova, S. N. MacMillan, J. M. Tanski and R. Waterman, Organometallics 2009, 28, 573-581; s) A. J. Roering, S. E. Leshinski, S. M. Chan, T. Shalumova, S. N. MacMillan, J. M. Tansk and R. Waterman, Organometallics 2010, 29, 2557-2565; t) M. B. Ghebreab, D. K. Newsham and R. Waterman, Dalton Trans. 2011, 40, 7683-7685; u) A. J. Roering, L. T. Elrod, J. K. Pagano, S. L. Guillot, S. M. Chan, J. M. Tanski and R. Waterman, Dalton Trans. 2013, 42, $1159-1167$; v) M. B. Ghebreab, C. A. Bange and R. Waterman, J. Am. Chem. Soc. 2014, 136, 9240-9243; w) A. T. Normand, C. G. Daniliuc B. Wibbeling, G. Kehr, P. Le Gendre and G. Erker, Chem. Eur. J. 2016, 22, 4285-4293.

[4] See refs 1, 3a-b, 3d and a) H. Bürger and H.-J. Neese, Zeit. Anorg Allg. Chem. 1969, 370, 275-282; b) J. G. Kenworthy, J. Myatt and P. F. Todd, J. Chem. Soc. Chem. Commun. 1969, 263-264; c) J. G. Kenworthy, J. Myatt and P. F. Todd, J. Chem. Soc. B 1970, 791-794; d) J. G. Kenworthy, J. Myatt and M. C. R. Symons, J. Chem. Soc. A 1971, 3428-3430; e) H. Bürger and H. J. Neese, Inorg. Nucl. Chem. Lett. 1970, 6, 299-304; f) H. Köpf and R. Voigtländer, Chem. Ber. 1981, 114, 2731-2743; g) B. L. Benac and R. A. Jones, Polyhedron 1989, 8 , 1774-1777; h) D. G. Dick and D. W. Stephan, Organometallics 1990 , 9, 1910-1916; i) D. G. Dick and D. W. Stephan, Can. J. Chem. 1991 69, 1146-1152; j) D. G. Dick and D. W. Stephan, Organometallics 1991, 10, 2811-2816; k) R. Payne, J. Hachgenei, G. Fritz and D. Fenske, Z. Naturforsch. B 1986, 41, 1535-1540; I) D. Fenske, A Grissinger, E. M. Hey-Hawkins and J. Magull, Zeit. Anorg. Allg. Chem 1991, 595, 57-66; m) D. G. Dick, Z. Hou and D. W. Stephan, Organometallics 1992, 11, 2378-2382; n) J. Ho and D. W. Stephan, Inorg. Chem. 1994, 33, 4595-4597; o) S. Xin, H. G. Woo, J. F. Harrod, 
E. Samuel and A.M. Lebuis, J. Am. Chem. Soc. 1997, 119, 53075313; p) M. Schaffrath, A. Villinger, D. Michalik, U. Rosenthal and A. Schulz, Organometallics 2008, 27, 1393-1398.

[5] a) R. Shu, L. Hao, J. F. Harrod, H.-G. Woo and E. Samuel, J. Am. Chem. Soc. 1998, 120, 12988-12989; b) J. D. Masuda, A. J. Hoskin, T. W. Graham, C. Beddie, M. C. Fermin, N. Etkin and D. W. Stephan, Chem. Eur. J. 2006, 12, 8696-8707; c) A. Perrier, V. Comte, C. Moïse and P. Le Gendre, Chem. Eur. J. 2010, 16, 64-67.

[6] a) F. Basuli, J. Tomaszewski, J. C. Huffman and D. J. Mindiola, J. Am. Chem. Soc. 2003, 125, 10170-10171; b) F. Basuli, L. A. Watson, J. C. Huffman and D. J. Mindiola, Dalton Trans. 2003, 4228-4229; c) B. C. Bailey, J. C. Huffman, D. J. Mindiola, W. Weng and O. V. Ozerov Organometallics 2005, 24, 1390-1393; d) G. Zhao, F. Basuli, U. J. Kilgore, H. Fan, H. Aneetha, J. C. Huffman, G. Wu and D. J. Mindiola, J. Am. Chem. Soc. 2006, 128, 13575-13585; e) B. F. Wicker, J. Scott, J. G. Andino, X. Gao, H. Park, M. Pink and D. J. Mindiola, J. Am. Chem. Soc. 2010, 132, 3691-3693.

[7] a) A. T. Normand, C. G. Daniliuc, B. Wibbeling, G. Kehr, P. Le Gendre and G. Erker, J. Am. Chem. Soc. 2015, 137, 10796-10808; b) A. T. Normand, C. G. Daniliuc, G. Kehr, P. Le Gendre and G. Erker, Dalton Trans. 2016, 45, 3711-3714.

[8] F. Silveira, L. M. T. Simplício, Z. N. d. Rocha and J. H. Z. d. Santos, Appl. Cat. A 2008, 344, 98-106.

[9] This was first observed by Issleib in 1964, see ref 1a. In this case further reduction of $\left[\mathrm{TiCl}_{4}\right.$.(2THF)] to $\mathrm{Ti}(\mathrm{II})$ gave the intriguing homoleptic complex [Ti( $\left.\left.\mathrm{PCy}_{2}\right)_{2}\right]$.

[10] The phosphinyl radical then recombines to form a diphosphane $\left(\mathrm{R}_{2} \mathrm{P}-\mathrm{PR} \mathrm{R}_{2}\right.$ ).

[11] a) H. Bürger and H.-J. Neese, Zeit. Anorg. Allg. Chem. 1969, 370, 275-282; b) H. Bürger and H. J. Neese, Inorg. Nucl. Chem. Lett. 1970, 6, 299-304.

[12] cationic $d^{0}$ phosphidotitanocene complexes $\left[\mathrm{Cp}_{2} \mathrm{TiP}\left(\mathrm{SiMe}_{3}\right)_{2}\right]^{+}$ and $\left[\mathrm{Cp}_{2} \mathrm{Ti}\left(\mathrm{PPh}_{2}\right)\left(\mathrm{PMe}_{3}\right)\right]^{+}$have previously been envisaged from a theoretical perspective : a) M. Ehrig, W. Koch and R. Ahlrichs, Chem. Phys. Lett. 1991, 180, 109-113; b) J. R. Rogers, T. P. S. Wagner and D. S. Marynick, Inorg. Chem. 1994, 33, 3104-3110.

[13] a) P. Le Gendre, M. Picquet, P. Richard and C. Moïse, J. Organomet. Chem. 2002, 643-644, 231-236; b) A. T. Normand, P. Richard, C. Balan, C. G. Daniliuc, G. Kehr, G. Erker and P. Le Gendre, Organometallics 2015, 34, 2000-2011.

[14] The first equivalent of phosphide acts as a sacrificial reductant, generating $\mathrm{R}_{2} \mathrm{P}-\mathrm{PR}_{2}$ as a by-product.

[15] J. W. Lauher and R. Hoffmann, J. Am. Chem. Soc. 1976, 98, $1729-1742$.

[16] as noted elsewhere in the case of amidoziroconcene cations (ref 7a), the lone pair of phosphorus would have to be in the equatorial plane of the bent $\mathrm{Cp}_{2} \mathrm{M}$ fragment for $\pi$ interactions to occur.

[17] B. Cordero, V. Gomez, A. E. Platero-Prats, M. Reves, J. Echeverria, E. Cremades, F. Barragan and S. Alvarez, Dalton Trans. 2008, 2832-2838.

[18] a) M. Nishio, Y. Umezawa, K. Honda, S. Tsuboyama and H. Suezawa, CrystEngComm 2009, 11, 1757-1788; b) M. Nishio, CrystEngComm 2004, 6, 130-158.

[19] a) Y. Umezawa and M. Nishio, Bioorg. Med. Chem. 1998, 6, 493504; b) X. Xu, B. Pooi, H. Hirao and S. H. Hong, Angew. Chem. Int. Ed. 2014, 53, 1283-1287.

[20] In order to circumvent hydrolysis by residual water, measurements were conducted on $10^{-2} \mathrm{M}$ solutions of the complexes in $0.1 \mathrm{~mm}$ cells

[21] a) D. Escudero, A. D. Laurent and D. Jacquemin Time-Dependent Density Functional Theory: A Tool to Explore Excited States, in Handbook of Computational Chemistry, (Ed. J. Leszczynski), Springer, Dordrecht, 2015; b) Z. Li and W. Liu, J. Chem. Theory Comput. 2016, 12, 2517-2527.

[22] a) S. L. Borkowsky, N. C. Baenziger and R. F. Jordan, Organometallics 1993, 12, 486-495; b) W. Ahlers, B. Temme, G. Erker, R. Fröhlich and F. Zippel, Organometallics 1997, 16, 1440-1444.

[23] We have previously used phi as an indicator of $\pi$ interactions between $\mathrm{Zr}$ and $\mathrm{N}$ or $\mathrm{P}$ in zirconocene complexes, see ref $7 \mathrm{a}$.

[24] It is interesting to note that a clear $\pi$ interaction was found by Alhrichs in the Ti(III) $\left[\mathrm{Cp}_{2} \mathrm{TiP}\left(\mathrm{SiMe}_{3}\right)_{2}\right]$ complex (ref 12a). The Ti-P $\pi$ interaction in this complex is possible because the metallocene fragment is supported only by the phosphide ligand : therefore, the single electron on titanium and the pri electrons on phosphorus occupy orthogonal orbitals This is no longer possible in complexes 2 in which the titanium atom is tetracoordinated: all $d$ orbitals are involved in bonds and the single electron is bound to interact with the lone pair of the phosphido ligand. This leads to a bent geometry, a classical situation in phosphido ligand chemistry (see ref 2d).

[25] ${ }^{1} \mathrm{H}$ NMR signals were assigned unambiguously through ${ }^{1} \mathrm{H}-{ }^{13} \mathrm{C}$ correlation experiments, i.e. HSQC and HMBC. Also, the ${ }^{31} \mathrm{P}$ spectrum of $\mathbf{3 b}$ shows that the hydrogens on $\mathrm{C} 11$ couple with P1, not P2. See supporting information.

[26] O. Kühl The Range of Chemical Shifts, Coupling Constants, and What Influences Each, in Phosphorus-31 NMR Spectroscopy: A Concise Introduction for the Synthetic Organic and Organometallic Chemist, (Ed. O. Kühl), Springer Berlin Heidelberg, Berlin, Heidelberg, 2008, pp. 7-23.

[27] Differences between ${ }^{3}{ }_{\mathrm{PH}}$ coupling constants in $\mathrm{CpCH}_{2} \mathrm{CH}_{2} \mathrm{PR}_{2}$ ligands have been observed before, see for example Janssen, $\mathrm{K}$.; Butenschon, H., New J. Chem. 2011, 35, 2287-2298.

[28] The exact chemical shift could not be ascertained due to multiple overlaps in the ${ }^{1} \mathrm{H}$ NMR spectrum of $\mathbf{3 d}$.

[29] S. Halbert, C. Copéret, C. Raynaud and O. Eisenstein, J. Am. Chem. Soc. 2016, 138, 2261-2272.

[30] We also observed small intensity $\left(\varepsilon=2210-3220 \mathrm{~cm}^{-1} \cdot \mathrm{M}^{-1}\right)$ shouldering bands in the UV region $(\mathbf{3 b}->348 \mathrm{~nm} ; \mathbf{3 c}>>342 \mathrm{~nm} ; \mathbf{3 d}$ $\rightarrow 346 \mathrm{~nm}$ ), although we were unable to assign them through DFT calculations.

[31] although the absence of $\left(\mathrm{PCy}_{2}\right)_{2}$ is surprising in the case of $\mathbf{3 f}$, it could just be that the presence of $\mathrm{PCy}_{2} \mathrm{H}$ in the reaction mixture prevents the phosphinyl radical from dimerizing, instead promoting other termination pathways, e.g. $\mathrm{H}$ abstraction from the solvent.

[32] Complex $\mathrm{E}$ was characterized in $\mathrm{C}_{6} \mathrm{D}_{5} \mathrm{Br}$ at $299 \mathrm{~K}$, see ref $7 \mathrm{a}$.

[33] a) J. Y. Lan and G. B. Schuster, J. Am. Chem. Soc. 1985, 107,

$6710-6711$; b) S. T. Murphy, C. Zou, J. B. Miers, R. M. Ballew, D. D.

Dlott and G. B. Schuster, J. Phys. Chem. 1993, 97, 13152-13157; c)

O. Grinevich, P. Serguievski, A. M. Sarker, W. Zhang, A. Mejiritski and

D. C. Neckers, Macromolecules 1999, 32, 328-330.

[34] Y. Hasegawa, G. Kehr, S. Ehrlich, S. Grimme, C. G. Daniliuc and G. Erker, Chem. Sci. 2014, 5, 797-803.

[35] A. T. Normand, C. G. Daniliuc, B. Wibbeling, G. Kehr, P. Le Gendre and G. Erker, Chem. Eur. J. 2016, 22, 4285-4293.

[36] Gaussian 09. Revision D. 01. Frisch. M. J. et al. Gaussian. Inc., Wallingford CT, 2009

[37] a) F. Weigend, Phys. Chem. Chem. Phys. 2006, 8, 1057-1065 b) F. Weigend and R. Ahlrichs, Phys. Chem. Chem. Phys. 2005, 7, 3297-3305.

[38] a) B. Mennucci, J. Tomasi, R. Cammi, J. R. Cheeseman, M. J. Frisch, F. J. Devlin, S. Gabriel and P. J. Stephens, J. Phys. Chem. A 2002, 106, 6102-6113; b) J. Tomasi, B. Mennucci and R. Cammi, Chem. Rev. 2005, 105, 2999-3093.

[39] W. Humphrey, A. Dalke and K. Schulten, J. of Mol. Graph. 1996, 14, 33-38.

[40] R. L. Martin, J. Chem. Phys. 2003, 118, 4775-4777

[41] R. G. Hadt, V. N. Nemykin, J. G. Olsen and P. Basu, Phys. Chem. Chem. Phys. 2009, 11, 10377-10384.

[42] E. Lerayer, P. Renaut, S. Brandès, H. Cattey, P. Fleurat-Lessard, G. Bouhadir, D. Bourissou and J.-C. Hierso, Inorg. Chem. 2017, 56, 1966-1973

[43] a) L. Goerigk and S. Grimme, J. Chem. Theory Comput. 2011, 7, 291-309; b) N. B. Balabanov and K. A. Peterson, J. Chem. Phys. 2005, 123, 064107.

[44] W. Kutzelnigg, U. Fleischer and M. Schindler, (Berlin, Heidelberg) 1991, pp. 165-262.

[45] https://bse.pnl.gov/bse/portal, accessed 04/05/2016. 